\title{
Firing of Hippocampal Neurogliaform Cells Induces Suppression of Synaptic Inhibition
}

\author{
Gengyu Li, ${ }^{1}$ Robert Stewart, ${ }^{1}$ Marco Canepari, ${ }^{2,3,4}$ and Marco Capogna ${ }^{1}$ \\ ${ }^{1}$ Medical Research Council Anatomical Neuropharmacology Unit, Department of Pharmacology, University of Oxford, Oxford 0X1 3TH, United Kingdom; ${ }^{2}$ Inserm \\ U836, Team 3, Grenoble Cedex 09, France, ${ }^{3}$ Université Joseph Fourier, Grenoble Institut des Neurosciences and Laboratoire Interdisciplinare de Physique, CNRS \\ UMR 5588, Grenoble Cedex 09, France, and ${ }^{4}$ Laboratories of Excellence, Ion Channel Science and Therapeutics, Inserm U836, Grenoble Cedex 09, France
}

Little is known about how neuron firing recorded in vivo retrogradely influences synaptic strength. We injected the firing of a rat hippocampal neurogliaform cell (NGFC), a widely expressed GABAergic neuron type, detected in vivo during theta rhythm, into NGFCs of rat or neuronal nitric oxide synthase (nNOS)-Cre-tdTomato mouse recorded in vitro. We found that the "in vivo firing pattern" produced a transient firing-induced suppression of synaptic inhibition (FSI) evoked by a presynaptic NGFC. Imaging experiments demonstrate that FSI was associated with action potential backpropagation (bAP) and a supralinear increase in dendritic Ca ${ }^{2+}$. The application of the L-type $\mathrm{Ca}^{2+}$ channel antagonist nimodipine blocked FSI. Further pharmacological experiments, such as the application of a nitric oxide-sensitive guanylyl cyclase (NO-sGC) receptor antagonist, a NOS inhibitor, and NO donors, suggested that NO released from postsynaptic cells mediated FSI and likely activated presynaptic receptors to inhibit GABA release. The in vivo firing pattern modulated the size of unitary EPSPs impinging on NGFCs through FSI and not via a direct effect on excitatory synaptic transmission. Our data demonstrate: (1) retrograde signaling initiated by in vivo firing pattern, (2) interneuron bAPs detected with fast temporal resolution, and (3) a novel role for NO expressed by specific interneuron types.

Key words: interneuron; hippocampus; retrograde messengers; nitric oxide; synaptic transmission; imaging

\section{Introduction}

Various GABAergic cells contain different $\mathrm{Ca}^{2+}$-binding proteins (e.g., calbindin, calretinin, and parvalbumin) or peptides (e.g., cholecystokinin, somatostatin, and neuropeptide Y; Klausberger and Somogyi, 2008). The cell-specific presence of such cell markers is often used for a neurochemical classification of interneuron diversity (Maccaferri and Lacaille, 2003). For example, the specific expression of calbindin, calretinin, and parvalbumin identifies groups of interneurons with different geometry of dendritic architecture, postsynaptic target specificity, and synaptic input density (Gulyás et al., 1999). Moreover, neurochemical markers are used to scrutinize the selective susceptibility of specific interneurons to pathological conditions, such as epilepsy (Cossart et al., 2001) and ischemia (Freund et al., 1992). In contrast to the neurochemical data, information on the physiological role of interneuron markers is scant, albeit there are some exceptions. For example, parvalbumin (PV), which labels var-

\footnotetext{
Received July 18, 2013; revised Dec. 3, 2013; accepted Dec. 6, 2013.

Author contributions: G.L. and M. Capogna designed research; G.L. and M. Canepari performed research; G.L. and R.S. analyzed data; M. Capogna wrote the paper.

This work was supported by the Medical Research Council, UK (award U138197106). We thank Katherine Whitworth for preparing the solutions and help with resectioning slices, and together with Liz Norman for generating and breeding the nNOS-Cre-tdTomato mice, Dr. Jeremy Graham (Cairn Research, Faversham, UK) for help to set up the laser-illumination system to detect voltage-sensitive dye signals, and Ben Micklem for technical assistance on immunohistochemistry analysis. We also thank Thomas Klausberger and Peter Somogyi for the use of firing patterns recorded in vivo in hippocampal NGFCs, and Dr. Alberto Bacci (ICM Paris), Dr. Michael Bazelot, and Marco Bocchio (MRC ANU) for their comments on the paper.

Correspondence should be addressed to Dr. Marco Capogna, Medical Research Council Anatomical Neuropharmacology Unit, Mansfield Road, 0xford, 0X1 3TH, UK. E-mail: marco.capogna@pharm.ox.ac.uk.

DOI:10.1523/JNEUROSCI.3046-13.2014

Copyright $\odot 2014$ the authors $\quad 0270-6474 / 14 / 341280-13 \$ 15.00 / 0$
}

ious types of interneurons (Klausberger and Somogyi, 2008) and is a slow $\mathrm{Ca}^{2+}$ buffer (Baimbridge et al., 1992), contributes to shortterm synaptic depression evoked by PV-expressing interneurons, and is likely to prevent the harmful effects of excessive $\mathrm{Ca}^{2+}$ accumulation in pathological conditions (Caillard et al., 2000). The neuropeptide $\mathrm{Y}$, which is also expressed by several interneuron types (Karagiannis et al., 2009), is likely to be an endogenous anti-epileptic peptide in the hippocampus (Colmers et al., 1991).

The interneurons of the hippocampus that express the neuronal nitric oxide synthase (nNOS) are very abundant (Fuentealba et al., 2008). The nNOS-expressing neurons comprise some CA1 pyramidal neurons and several types of interneurons including: neurogliaform cells (NGFCs; Price et al., 2005), ivy cells (Fuentealba et al., 2008), interneuron-specific interneurons coexpressing the vasoactive intestinal peptide and calretinin, a subset of PV-expressing interneurons of the dentate gyrus, a subset of somatostatin-expressing interneurons, and projection cells with the soma close to the subiculum (Tricoire and Vitalis, 2012). Despite their wide distribution, the functional role of NO in nNOS-expressing hippocampal interneurons is not known. In the neocortex, the NO released by NGFCs has been proposed to regulate neurovascular coupling and blood flow (Cauli et al., 2004).

To study the physiological role of nNOS-expressing interneurons of the hippocampus, we capitalized on a database of firing patterns of anatomically identified hippocampal interneurons recorded in vivo (Klausberger and Somogyi, 2008). We injected the firing of an NGFC detected in vivo during theta rhythm (Fuentealba et al., 2010) into NGFCs recorded in vitro. We chose NGFCs because a good 
proportion of them express nNOS, they are frequently synaptically coupled, they display few and short dendrites well preserved in vitro, and they are biophysically compact (Vida et al., 1998; Price et al., 2005; Tricoire et al., 2010). These features make them an excellent cell type to study NO-dependent signaling by using unitary synaptic transmission and dendritic imaging. We found that the NGFC in vivo firing pattern elicited a depolarization-induced suppression of inhibition (DSI)-like phenomenon (Llano et al., 1991; Pitler and Alger, 1992). We termed this phenomenon firinginduced suppression of inhibition (FSI). We report here the mechanisms, the signaling, and the role of FSI on NGFC synaptic integration.

\section{Materials and Methods}

Slice preparation. All procedures involving animals were performed using methods approved by the United Kingdom Home Office and in accordance with The Animals (Scientific Procedures) Act, 1986. Juvenile male and female rats (P15-P22) or nNOS-Cre-tdTomato male and female mice (P29-P40) were anesthetized with isoflurane and decapitated. The brain was carefully removed and mounted on the plate of a vibratome (Microm HM $650 \mathrm{~V}$, ThermoFisher Scientific) in ice-cold ACSF containing the following (in mM): $85 \mathrm{NaCl}, 25 \mathrm{NaHCO}_{3}, 2.5 \mathrm{KCl}, 1.25 \mathrm{NaH}_{2} \mathrm{PO}_{4}$, $0.5 \mathrm{CaCl}_{2}, 7 \mathrm{MgCl}_{2}, 10$ glucose, 75 sucrose saturated with $95 \% \mathrm{O}_{2}$, and $5 \% \mathrm{CO}_{2}, \mathrm{pH} \sim 7.3$. Horizontal sections (thickness, $325 \mu \mathrm{m}$ ) consisting of the dorsal hippocampus and attached entorhinal cortex were prepared using a vibratome. During the initial period of slice storage ( $\sim 20 \mathrm{~min})$, the cutting solution was replaced with normal ACSF (containing the following in mu: $130 \mathrm{NaCl}, 24 \mathrm{NaHCO}_{3}, 3.5 \mathrm{KCl}, 1.25 \mathrm{NaH}_{2} \mathrm{PO}_{4}, 2.5$ $\mathrm{CaCl}_{2}, 1.5 \mathrm{MgSO}_{4}, 10$ glucose saturated with $\left.95 \% \mathrm{O}_{2}, 5 \% \mathrm{CO}_{2}, \mathrm{pH} 7.3\right)$. Slices were then maintained at room temperature $\left(18^{\circ}-22^{\circ} \mathrm{C}\right)$.

Acute slices were then placed in a recording chamber mounted on the stage of an upright microscope (Olympus BX 51WI, or Axioscope Zeiss) equipped with immersion differential interference contrast objectives $(40 \times, 60 \times)$ coupled to an infrared camera system (Hamamatsu), superfused at a rate of $\sim 2 \mathrm{ml} / \mathrm{min}$ with oxygenated recording ACSF, and maintained at a temperature of $33 \pm 1{ }^{\circ} \mathrm{C}$.

Electrophysiology recordings and analysis. Whole-cell recordings were performed using EPC10/3 or EPC9/2 amplifiers (HEKA). Rat interneurons with the soma in the stratum lacunosum moleculare (SLM) were identified based on soma shape and size under infrared video microscopy. Mouse interneurons with the soma in the SLM-expressing tdTomato under fluorescence illumination were selectively recorded. Borosilicate patch pipettes were pulled (Zeitz puller, DMZ), and filled with a solution containing the following (in $\mathrm{mM}$ ): $88 \mathrm{KCl}, 42 \mathrm{~K}$-gluconate, 10 HEPES, $10 \mathrm{Na}_{2}$ Phosphocreatine, $4 \mathrm{Mg}$-ATP, $0.3 \mathrm{Na}$-GTP, pH 7.3 with $\mathrm{KOH}$, to increase the driving force for $\mathrm{Cl}^{-}$ions $(\mathrm{ECl}=-11 \mathrm{mV})$ to the extent that the IPSC polarity was inward at the holding potential $\left(V_{h}\right)$ of $-65 \mathrm{mV}$. In dynamic clamp experiments performed in current-clamp mode, the intracellular solution contained the following (in mM): 126 K-gluconate, 10 HEPES, $10 \mathrm{Na}_{2}$ Phosphocreatine, $4 \mathrm{KCl}, 4 \mathrm{Mg}$-ATP, 0.3 $\mathrm{Na}-\mathrm{GTP}$, pH 7.3 with $\mathrm{KOH}$, the osmolarity was $270-280 \mathrm{mOsmol}$. Biocytin was added to the intracellular solutions before recording at a final concentration of 2-4 mg/ml. Pipettes had resistances of 5-6 $\mathrm{M} \Omega$ when filled with the internal solution containing $88 \mathrm{~mm} \mathrm{KCl}$. Access resistance was always monitored to ensure the stability of recording conditions. Cells were only accepted for analysis if the initial series resistance was less than or equal to $20 \mathrm{M} \Omega$ and did not change by $>20 \%$ throughout the recording period. No correction was made for the junction potential between the pipette and the ACSF, and therefore the recorded membrane potential, as calculated post hoc using a junction potential calculator, was 16 and $11 \mathrm{mV}$ more depolarized than the true membrane potential, for $\mathrm{K}$-gluconate and high- $\mathrm{Cl}^{-}$intracellular solution, respectively.

Action currents or potentials were elicited in a presynaptic cell by using a short depolarizing voltage step (from the holding potential of $-68 \mathrm{mV}$ to 0 $\mathrm{mV}, 3 \mathrm{~ms})$ or a short depolarizing current step $(500-1000 \mathrm{pA} \times 3 \mathrm{~ms}$, from $-68 \mathrm{mV}$ ). The corresponding unitary IPSC (UIPSC) or unitary IPSP (UIPSP) was recorded in a synaptically coupled postsynaptic neuron or in the presynaptic neuron as an autaptic IPSC (aIPSC). Postsynaptic and autaptic currents were filtered at $3 \mathrm{kHz}$ and recorded with a sampling rate of $5 \mathrm{kHz}$. Spontaneous IPSCs (sIPSCs) were also recorded at $V_{h}=-65 \mathrm{mV}$ filtered at $3 \mathrm{kHz}$ with a sampling rate of $10 \mathrm{kHz}$ for $120 \mathrm{~s}$.

The in vivo firing sequence was recorded in an identified NGFC in an anesthetized rat with the juxtacellular/extracellular method during theta oscillations and previously published (Fuentealba et al., 2010). This firing sequence lasting $60 \mathrm{~s}$ was transformed as voltage pulses $(100 \mathrm{mV}, 1 \mathrm{~ms}$ each) using MATLAB (MathWorks) software, and injected as stimulus protocol to induce FSI into whole-cell patch-clamped cells using PatchMaster (Heka) software. The stimuli evoked a train of action potentials in vitro that exactly matched the sequence of action potentials detected in vivo. A recorded pair was classified as having FSI if the UIPSC or uIPSP evoked $125-250 \mathrm{~ms}$ after the end of the stimulation protocol applied to the postsynaptic cell was decreased $>5 \%$ followed by full recovery of the peak amplitude of the response. In the majority of the cases, the stimulation protocol was repeated several times (typically three times) for each experiment followed by at least two stimulations with recovery.

Electrophysiological data were analyzed offline using custom made MATLAB software. For FSI analysis, FSI amplitude was measured as $1-\frac{\operatorname{IPSC}(\mathrm{P})_{\mathrm{FSI}}}{\operatorname{IPSC}(\mathrm{P})_{\text {control }}}$, where $\operatorname{IPSC}(\mathrm{P})_{\mathrm{FSI}}$ is the amplitude of IPSC $(\mathrm{P}) 125$ or $250 \mathrm{~ms}$ after the stimulus protocol, and $\operatorname{IPSC}(\mathrm{P})_{\text {control }}$ is the average amplitude of three IPSC $(\mathrm{P}) \mathrm{s}$ acquired before conditional protocol. For kinetics analysis, the $20-80 \%$ rise time and decay time constant $\left(\tau_{\text {syn }}\right)$ were calculated by fitting a single exponential in the form of $A e^{b x}+C$ in each trace. The decay of the uIPSCs could also be fitted with a double exponential, and the weighted decay time constant was calculated using the following formula: $\tau_{\mathrm{w}}=\tau_{1} A_{1}+\tau_{2}\left(1-A_{1}\right)$, where $\tau_{\mathrm{w}}$ is the weighted decay time constant, $\tau_{1}$ and $\tau_{2}$ are the time constants of the first and second exponential functions, respectively, and $A_{1}$ is the proportion of the peak amplitude of the averaged uIPSC that is contributed by $\tau_{1}$. For passive and active electrophysiological property analysis: the input resistance $\left(R_{\text {in }}\right)$ was calculated as the inverse of the gradient of the linear fit from an $I / V$ plot of the recorded cell (current injected against steady-state voltage response); membrane time constant $\left(\tau_{\text {mem }}\right)$ was calculated by fitting a single exponential $A e^{b x}+C$; membrane capacitance was calculated as $\tau_{\mathrm{mem}} / R_{\mathrm{in}}$; the sag rectification ratio was calculated from the membrane potential at the end of $500 \mathrm{~ms}$ hyperpolarizing divided by the largest membrane potential change observed in response to a current step of $-200 \mathrm{pA}$; and the adaptation index was defined as the interspike interval between the last versus the first action potential evoked by a depolarizing current pulse lasting $500 \mathrm{~ms}$. The peak amplitude and half-width were measured from the initial point of the rising phase of the action potential. The coefficient of variation (CV) for the stimulation protocol was calculated as the SD of interspike intervals/mean of interspike intervals.

Synthetic (dynamic clamp) EPSPs (dEPSPs) were applied through the patch pipette using a synaptic module (SM-1) conductance injection amplifier (Cambridge Conductance). The dynamic conductance waveform for an EPSP was based on the magnitude, kinetics, and reversal potential of the EPSC experimentally evoked by minimal stimulation in the same cell in voltage-clamp before the dynamic clamp experiment (dEPSP peak conductance $=0.5-2 \mathrm{nS}, 20-80 \%$ rise time $=0.6-0.7 \mathrm{~ms}$, decay $\tau=3-4 \mathrm{~ms}$, reversal potential set at $0 \mathrm{mV}$ ). dEPSP data were analyzed with scripts written in MATLAB. Ten dEPSPs were applied at 80 $\mathrm{Hz}$ and the peak amplitude of each dEPSP was calculated from its baseline before, during, and after FSI. To obtain dEPSPs, minimal extracellular stimulation was conducted by applying rectangular pulses of current $(0.4 \mathrm{~ms}$ width, intensity range: $10-15 \mu \mathrm{A})$ delivered through an isolation unit (A360 Stimulus Isolator, World Precision Instruments) to a monopolar patch pipette filled with ACSF placed closed to the recorded cell (5 $\mu \mathrm{M}$ gabazine and $50 \mu \mathrm{M}$ CGP35348 added to extracellular ACSF).

Paired or unpaired Student's $t$ tests, where appropriate, were performed with SPSS or Prism 4.0 (Graphpad Software). When other statistical tests have been used then they have been specified in the text. Statistical significance was set at $p<0.05$. Values presented in the text and figures represent the mean \pm SEM unless otherwise stated.

Voltage-sensitive dye and calcium imaging recordings and analysis. In voltage-sensitive dye (VSD) and $\mathrm{Ca}^{2+}$ imaging experiments, a low chlo- 
ride internal solution containing the following (in $\mathrm{mm}$ ): $140 \mathrm{~K}$-gluconate, 10 HEPES, 10 $\mathrm{Na}_{2}$ Phosphocreatine, $4 \mathrm{Mg}$-ATP, $0.3 \mathrm{Na}$-GTP, $\mathrm{pH} 7.3$ with $\mathrm{KOH}$ was used. The VSD JPW 1114 $(0.25-0.5 \mathrm{mg} / \mathrm{ml})$ was loaded into the cell by using the whole-cell patch-clamp recording of the cell soma described in detail previously (Canepari et al., 2008). Briefly, the whole-cell configuration used for dye loading lasted 30-40 min and then the patch pipette was removed from the cell by forming an outside-out patch. The cell was then incubated for additional 60-90 min to allow dye equilibration into dendrites and repatched with a dye-free pipette containing biocytin $(2-4 \mathrm{mg} / \mathrm{ml})$. Voltage fluorescence was excited with a $532 \mathrm{~nm}$, $300 \mathrm{~mW}$ solid state laser (model MLL532, $\mathrm{CNI}$ ) as described previously (Canepari et al., 2010). In $\mathrm{Ca}^{2+}$ imaging experiments, the lowaffinity indicators Oregon green 5N (OG5N) or Mag-Fura-2 (MF2) were added at $0.5 \mathrm{~mm}$ concentration to the internal solution. $\mathrm{Ca}^{2+}$ fluorescence was excited with an OptoFlash (Cairn Research) using either a $470 \mathrm{~nm}$ LED (for OG5N) or a $385 \mathrm{~nm} \mathrm{LED} \mathrm{(for} \mathrm{MF2),}$ mounted on the epifluorescence port of the microscope. The excitation light, either from the laser or the LED, was directed to a waterimmersion objective (Olympus $60 \times / 1.1 \mathrm{NA}$ ). Fluorescent images, demagnified by $0.25 \times$ or $0.38 \times$, were visualized with a high speed CCD camera NeuroCCD-SM (RedShirt Imaging) at a frame rate ranging between $125 \mathrm{~Hz}$ and 5 $\mathrm{kHz}$. The corresponding electrophysiological signals from the soma were recorded at a frequency ranging between $8 \mathrm{kHz}$ and $20 \mathrm{kHz}$. The CCD had $80 \times 80$ pixels covering an area of $125 \times 125 \mu \mathrm{m}$ with the $0.25 \times$ demagnifier and $82 \times 82 \mu \mathrm{m}$ with the $38 \times$ demagnifier. The area covered by a single pixel was $1.6 \times 1.6$ and $1 \times 1 \mu \mathrm{m}$ with the $0.25 \times$ and $0.38 \times$ demagnifiers, respectively. The dendritic regions analyzed in this study were within $20-120 \mu \mathrm{m}$ from the soma.

Both VSD and $\mathrm{Ca}^{2+}$ imaging data were analyzed with dedicated software written in MATLAB. Optical signals were initially expressed as fractional changes of fluorescence averaged from $4 \times 4$ (16 pixels) regions of interest and obtained from averages of four trials unless otherwise mentioned. The fractional change of fluorescence was computed as the change of fluorescence of each individual frame from the initial fluorescence divided by the initial fluorescence. A bleaching sweep (without signal) was acquired and subtracted from the signal sweeps. For calibration of VSD signals, a "reference" signal associated with a long lasting hyperpolarizing current pulse $(-50 /-100 \mathrm{pA}, 350 \mathrm{~ms})$ was injected into the soma and recorded ( $400 \mathrm{~ms} \times 9-16$ sweeps $)$ at low acquisition rate (typically 125 frames/s) using a moderate illumination (usually $3 \mathrm{~mW}$ ) to minimize bleaching and photo-toxicity. This signal should spread with minimal attenuation along the dendrites (Vetter et al., 2001), providing a uniform membrane potential change along the dendrite. Thus, because the VSD $\Delta F / F$ signal is linear with the membrane potential change, any $\Delta F / F$ can be converted into millivolts using the same procedure described previously (Canepari and Vogt, 2008) for cerebellar Purkinje end of the stimulus protocol.
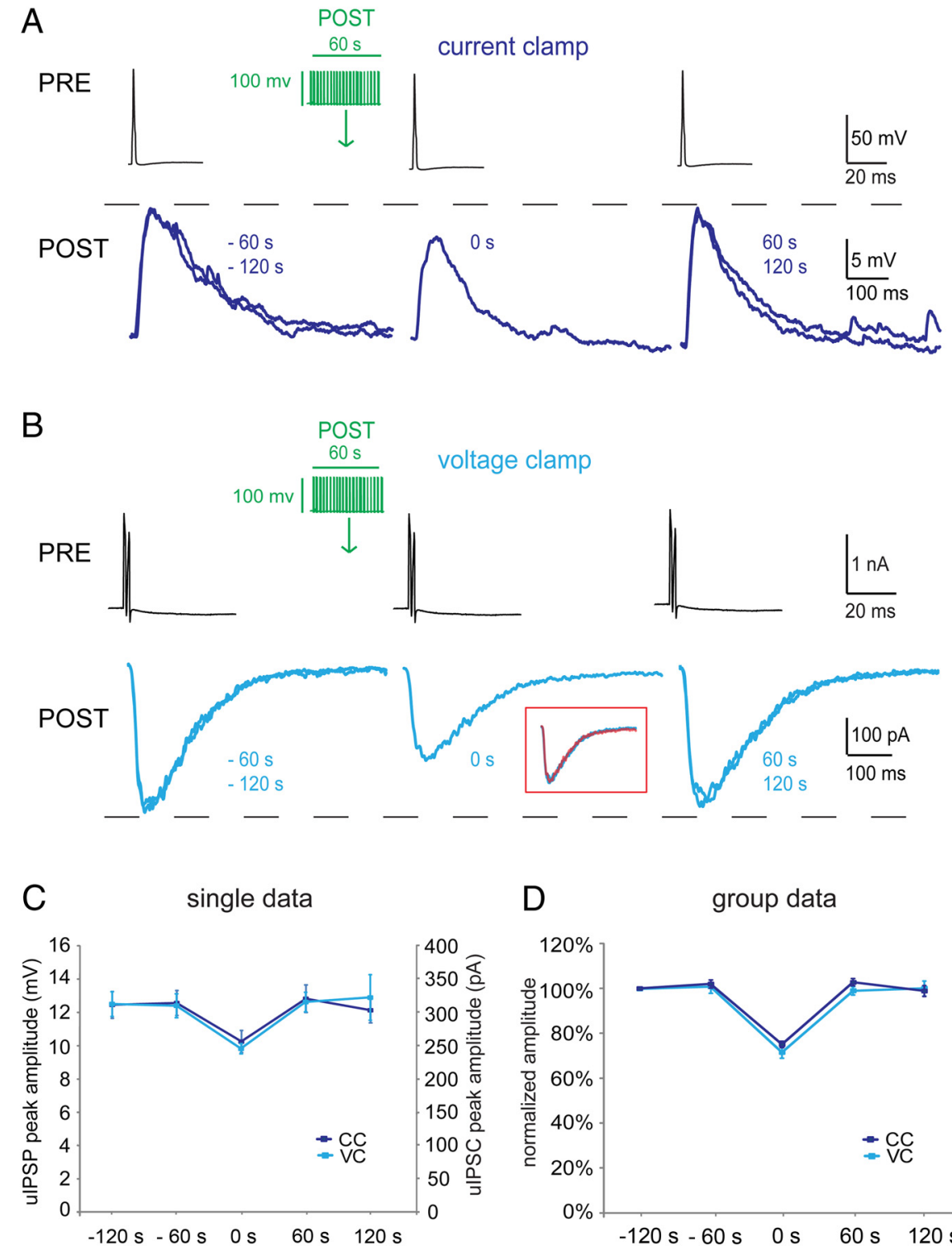

D group data

Figure 1. NGFC in vivo firing pattern induces a transient suppression of synaptic inhibition (FSI). A, NGFC paired recording in vitro, current-clamp mode, presynaptic action potentials (PRE, black traces) evoked depolarizing uIPSPs in a postsynaptic cell recorded with an electrode filled with $84 \mathrm{~mm} \mathrm{Cl}^{-}$solution (POST, left dark blue traces superimposed recorded 120 or 60 s before the stimulation protocol). Injection of firing recorded in vivo from an NGFC for $60 \mathrm{~s}$ (stimulation protocol) in the postsynaptic NGFC recorded in vitro induced a transient decrease of the amplitude of the uIPSP (POST, middle trace), that returned to the baseline level 60 and 120 s after the end of the stimulation protocol (right traces superimposed). $\boldsymbol{B}$, NGFC paired recording, voltage-clamp mode, presynaptic action currents (PRE, black traces) evoked inward uIPSCs in a postsynaptic cell recorded with an electrode filled with 84 $\mathrm{mm} \mathrm{Cl}^{-}$solution (POST, left light blue traces superimposed recorded 120 or 60 s before the stimulation protocol). Injection of in vivo NGFC firing for $60 \mathrm{~s}$ (stimulation protocol) in the postsynaptic NGFC induced a transient decrease of the amplitude of the ulPSC (middle trace), that returned to the baseline level 60 and $120 \mathrm{~s}$ after the end of the stimulation protocol (right traces superimposed). Inset, Scaled traces show no changes in the kinetics of the uIPSCs before and during FSI. C, Mean uIPSP (CC, current-clamp) or uIPSC (VC, voltage-clamp) peak amplitude before and after the stimulation protocol (repeated sequentially three times) for the cell pairs shown in $\boldsymbol{A}$ and $\boldsymbol{B}$; error bars are SEM. $\boldsymbol{D}$, summary of normalized peak amplitudes of uIPSPs (CC) or uIPSCs (VC) before and after the stimulation protocol in all pairs showing FSl; error bars are SEM ( $p<0.001, n=23$ for CC data, $n=25$ for VC data). In the graphs $\boldsymbol{C}$ and $\boldsymbol{D}$ of this and subsequent figures, 0 s indicates mean uIPSP or ulPSC amplitude detected 125 or $250 \mathrm{~ms}$ after the

neurons. The amplitude of the images resulted from the average value $\Delta F / F$ during a steady-state pulse (usually $50 \mathrm{~ms}$ ) subtracted from $\Delta F / F$ value immediately before the onset of the pulse, baseline $10-20 \mathrm{~ms} \Delta F / F$ mean value.

To calibrate fractional changes of OG5N fluorescence into changes of intracellular free $\mathrm{Ca}^{2+}\left(\Delta\left[\mathrm{Ca}^{2+}\right]\right.$ free $)$, we used the low-affinity indicator MF2 $\left(K_{\mathrm{d}}=25 \mu \mathrm{M}\right)$. When excited at $385 \mathrm{~nm}$, this indicator exhibits a 
A

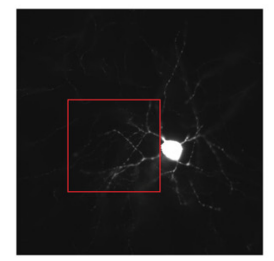

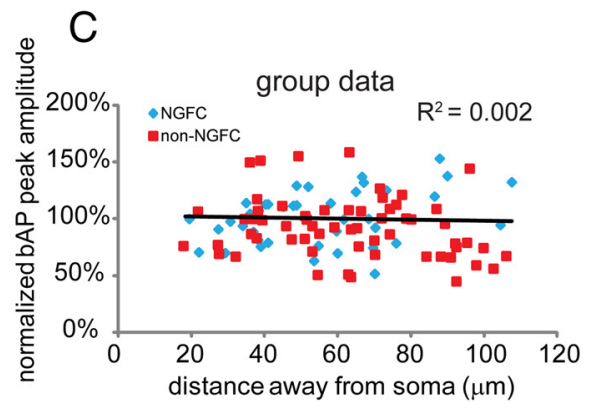

$\mathrm{D}$
$\mathrm{B}$

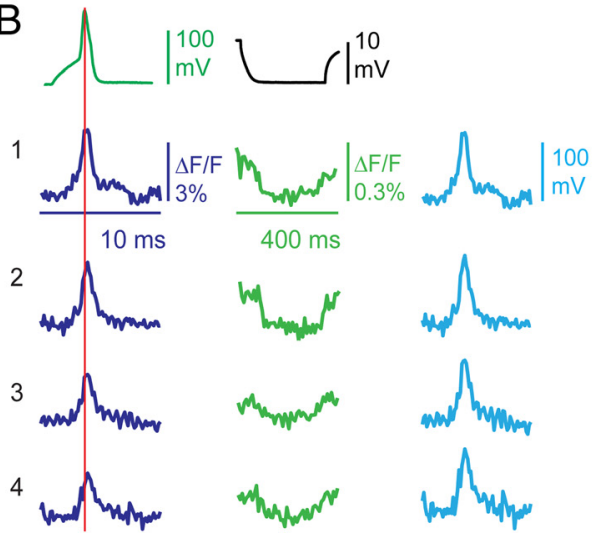

Soma Electrophysiology

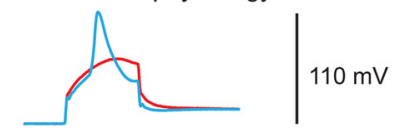

Dendrite $\triangle F / F$ control

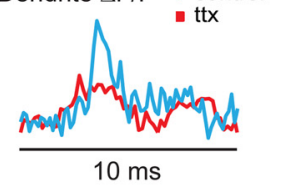

$100 \mathrm{mV}$ $100 \mathrm{mV}$

Figure 2. bAP along the dendrites of NGFCs or other interneurons of the SLM. A, Image of an NGFC (after biocytin-streptoavidinCy3 reaction) showing characteristic stellate dendrites (top, objective $\times 20$ ). This neuron was loaded with JPW-1114 and voltage imaging was performed from dendritic sites included in the red box; in particular, $\Delta F / F$ signals at the sites indicated $(1-4$, bottom, $4 \times 4$ pixels) were analyzed. $\boldsymbol{B}$, Left, A depolarizing current pulse ( $800 \mathrm{pA}, 3 \mathrm{~ms}$ ) induced a somatic AP recorded in current-clamp (green trace), and the corresponding $\Delta F / F$ signals from the site $1-4$ in $A$ is illustrated. The red vertical bar denotes the AP peak recorded from the soma. $\boldsymbol{B}$, Middle traces, Fractional changes of voltage fluorescence $(\Delta F / F)$ in response to a $\sim 10 \mathrm{mV}$ membrane potential hyperpolarization lasting $350 \mathrm{~ms}$ (average of 9 traces) injected into the soma and recorded from sites 1-4 of the dendrites; somatic current-clamp recording is illustrated on the top. $\boldsymbol{B}$, Right traces, $\Delta F / F$ of the bAPs peak amplitude calibrated with the corresponding $\Delta F / F$ induced by the hyperpolarizing current pulse recorded from regions $1-4$ of the dendrites. $C$, Group data of bAP peak amplitude recorded at different dendritic sites normalized to the bAP amplitude recorded at $20-30 \mu \mathrm{m}$ (shortest distance) from the soma. Note that bAPs occurs in NGFCs and in other interneurons of the SLM (non-NGFC) without any significant decrement (bAP peak amplitude detected at dendrites $>70 \mu \mathrm{m}$ or $\sim 20 \mu \mathrm{m}$ away from the soma was not significantly different, $p>0.5, n=24)$. D. Top trace, Effect of $1 \mu \mathrm{m}$ TTX on an AP recorded in current-clamp evoked by a depolarizing current pulse ( 800 $\mathrm{pA} \times 3 \mathrm{~ms}$, top traces). Bottom trace, Effect of $1 \mu \mathrm{m}$ TTX on $\Delta F / F b A P$ recorded from a dendrite of an NGFC. Blue traces, control; red traces, TTX. Note that TTX blocks the $\Delta F / F$ of the bAP, whereas it spares $\Delta F / F$ of the subthreshold depolarization evoked by the somatic subthreshold depolarizing pulse.

decrease in fluorescence associated with an increase in $\mathrm{Ca}^{2+}$ and the $\Delta\left[\mathrm{Ca}^{2+}\right]$ free can be estimated as $K_{\mathrm{d}} \cdot\left(F_{\min }-F\right) /\left(F-F_{\max }\right)$, where $F_{\text {min }}$ and $F_{\max }$ are the fluorescence at 0 and saturating $\mathrm{Ca}^{2+}$, respectively. This indicator has an excellent dynamic range, and in the study by Cueni et al. (2008) we have shown that at high concentrations $(>0.5 \mathrm{~mm}), F_{\min }$ and $F_{\max }$ can be approximated with the initial fluorescence and the slice autofluorescence, respectively. In addition MF2 fluorescence is not excited at $470 \mathrm{~nm}$, i.e., at the excitation wavelength of OG5N. Thus, in a series of calibration experiments, we added the two indicators together at $0.5 \mathrm{~mm}$ concentration in the patch pipette and monitored fluorescence signals associated with one to four action potentials to calibrate the OG5N fractional change of fluorescence into $\Delta\left[\mathrm{Ca}^{2+}\right]$ free.

Intracellular labeling and post hoc visualization of recorded cells. After recordings, the slices were immersed at $4^{\circ} \mathrm{C}$ for $12-24 \mathrm{~h}$ in a fixative solution containing the following: $4 \%$ paraformaldehyde, $15 \%(\mathrm{v} / \mathrm{v})$ saturated picric acid, and $0.1 \mathrm{~m}$ phosphate buffer ( $\mathrm{pH} 7.2-7.4)$. Then, gelatin-embedded slices were resectioned into $60-\mu \mathrm{m}$-thick sections. Sections were then incubated with streptavidin-Cy3 solution ( $93 \%$ of 0.1 M phosphate buffer, $6 \%$ of Triton X-100 at $3 \%$ and $1 \%$ of streptavidin$\mathrm{Cy} 3$ ) overnight before mounting and imaging them under a fluorescent microscope. Pictures of the location and the dendritic/axonal patterns of the recorded neurons were performed and stored. After this step, some sections were further processed to reveal the fine details of the processes of the cells using the diaminobenzidine (DAB) staining method. In brief, sections containing biocytin-filled cells were incubated in avidinbiotinylated horseradish peroxidase complex (1:100 dilution; ABC Kit, Vector Laboratories) followed by a peroxidase reaction using DAB (Sigma-Aldrich; 0.05\%) as the chromogen and $1 \% \mathrm{H}_{2} \mathrm{O}_{2}$ as the substrate. Sections were then mounted on gelatin-coated slides, air-dried, immersed in xylene-based mounting medium (Entellan; Merck), and coverslipped.

The nNOS-Cre-tdTomato mouse line was generated using methods described previously (Taniguchi et al., 2011). Tamoxifen administration was used to induce Cre activity in nNOS-expressing neurons. Tamoxifen was administrated by intraperitoneal injection at $2-5$ $\mathrm{mg} /$ dosage three times every other day from P21. When immunohistochemistry was performed on sections of nNOS-Cre-tdTomato mice, resectioned slices $(50 \mu \mathrm{M})$ were incubated with a primary antibody raised against nNOS (1:500 goat ab1376, Abcam) and tdTomato (1:500 Rat RFP 5F8, Chromotek) overnight at $4^{\circ} \mathrm{C}$ in $0.3 \%$ Triton $\mathrm{X}-100$ and $10 \%$ normal donkey serum containing PBS-azide buffer. The nNOS staining was revealed using AlexaFluor488-conjugated secondary antibody (1:500 donkey to goat, Invitrogen), and tdTomato staining was revealed using Cy3conjugated secondary antibody (1:1000 donkey to rat, Jackson ImmunoResearch).

For cell-counting experiments, resectioned slices of nNOS-Cre-tdTomato mice were visualized under a confocal microscope (Zeiss LSM $710)$. Images were acquired using the acquire SRS image stack workflow function in StereoInvestigator (MBF Bioscience), in which the whole hippocampus was included. Cell counting (interneurons and pyramidal cells) was performed offline: the digital copy of each section was opened in StereoInvestigator, the guard zone was $2 \mu \mathrm{m}$ and the probe length was $10 \mu \mathrm{m}$; only cells with soma in the probe zone were counted.

Chemicals and drugs. All drugs were applied to the recording preparation through the bath. Salts used in the preparation of the intracellular recording solution and ACSF were obtained from either BDH Laboratory Supplies or Sigma-Aldrich. Kynurenic acid, biocytin was purchased from SigmaAldrich, 6-Imino-3-(4-methoxyphenyl)-1(6H)-pyridazinebutanoic acid hydrobromide (SR95531), CGP35348, 1H-[1,2,4] Oxadiazolo[4,3a] quinoxal-in-1-1 (ODQ), NG-Nitro-L-arginine methyl ester hydrochloride (L-NAME), L-arginine, nimodipine, ryanodine, and U73122 were purchased from Tocris Bioscience).

\section{Results}

In vivo firing induces a transient suppression of synaptic inhibition

uIPSPs or uIPSCs were recorded from synaptically coupled putative NGFCs in the SLM of rat hippocampus in vitro. Due to high $\left[\mathrm{Cl}^{-}\right]_{\mathrm{i}}$ these events were depolarizing potentials (current-clamp recordings at $-68 \pm 2 \mathrm{mV}$ ) or inward currents (voltage-clamp recordings at $-68 \pm 2 \mathrm{mV}$ ). A firing sequence (60 s duration, average frequency and CV values: $8.3 \mathrm{~Hz}, 0.75$; stimulation protocol) recorded in a rat NGFC in vivo during theta oscillations (Fuentealba et al., 2010) was injected in current-clamp mode in a postsynaptic interneuron of the SLM recorded in vitro. This 
caused a transient decrease in the amplitude of the UIPSPs recorded in currentclamp occurring shortly after (125 or 250 $\mathrm{ms})$ the in vivo firing injection $(75 \pm 1.4 \%$ of control, $p<0.001$ ) in $23 / 70$ cell pairs tested (Fig. $1 A, C$ ). Likewise, the stimulation firing elicited a transient decrease in the amplitude of the uIPSCs recorded in voltage-clamp $(72.6 \pm 2.1 \%$ of control, $p<0.001$ ) in 25/54 cell pairs tested (Fig. $1 B, C)$. The kinetics of control and decreased uIPSCs evoked before and immediately after the stimulation protocol was similar (Fig. 1B, inset) (rise-time was $97 \pm$ $4 \%$ of control, $p>0.1$; weighted decay time constant was $98 \pm 12 \%$ of control, $p>0.1, n=9$ ), suggesting that presynaptic mechanisms were more likely than postsynaptic ones to underlie the decrease of the synaptic responses. Sixty seconds after the end of the stimulation protocol the uIPSPs or uIPSCs returned to control level and remained stable (interstimulus interval $=60 \mathrm{~s}$ ). Usually, it was possible to induce several transient depressions of the uIPSPs or uIPSCs by repeating cycles of the stimulation protocol followed by lowfrequency stimulations in the same cell pair (Fig. $1 C$, note the average values and SEM bars). We termed the transient depression of the UIPSPs or UIPSCs as FSI. Quantitatively, the FSI of the uIPSPs recorded in current-clamp was not significantly different from the FSI of the uIPSCs recorded in voltage-clamp $(p>0.1$; Fig. $1 D)$. Therefore, data arising from both recording modes were pooled and will be presented as such in the next sections. Most of the presynaptic neurons displayed aIPSCs. Interestingly, the stimulation protocol also induced FSI of the aIPSPs or aIPSCs in 6 of 30 pairs that also showed FSI of the postsynaptic UIPSPs or UIPSCs, although this transient depression was mild $(92.5 \pm 1.8 \%$ of control, $p<0.05$, data not shown).

Next we aimed to confirm that the recorded neurons in the SLM were NGFCs, because this layer of the hippocampus contains the soma of several other interneuron types (Vida et al., 1998; Klausberger, 2009; Capogna, 2011). Therefore, the recorded neurons were tested for the presence of the aIPSP occurring as a depolarizing potential (current-clamp mode) or an inward current (voltage-clamp mode) immediately after an action potential or current, the autaptic response being predictive of an NGFC (Karayannis et al., 2010). Furthermore, the kinetics of the postsynaptic uIPSCs were analyzed; when the rise-time was $>3$ $\mathrm{ms}$ and the decay time constant $>60 \mathrm{~ms}$, the presynaptic neuron was considered as an NGFC based on our previous observations (Karayannis et al., 2010). Furthermore, all neurons were filled with biocytin for subsequent analysis of the dendritic and axonal patterns. Based on these three criteria combined, we found that 41/48 presynaptic neurons displaying FSI were NGFCs, characterized by round somata, short, highly arborizing dendrites close to the soma and an axon which profusely arborized to cover the dendritic tree (Fig. 2A). In addition, five presynaptic cells were other types of interneurons including two putative perforant pathassociated interneurons, identified by the axonal branches segre- gated within the hippocampal fissure, and three putative cholecystokinin (CCK)-expressing basket neurons characterized by the flask-like shape of their soma. Two presynaptic interneurons could not be identified. Moreover, we successfully recovered substantial portions of the dendritic and axonal processes in 21 postsynaptic neurons showing FSI. Among them, 17 cells were identified as NGFCs, three cells as putative perforant pathassociated interneurons, and one cell was classified as a putative CCK-expressing basket cell. The NGFCs and few other interneurons of the SLM included in this study exhibited firing patterns and intrinsic electrophysiological responses (data not shown) similar to previous observations (Elfant et al., 2008).

Initial experiments ruled out that FSI was simply due to a transient and unspecific change in the postsynaptic membrane conductance. Specifically, application of a hyperpolarizing current pulse $(-150 \mathrm{pA}, 350 \mathrm{~ms})$ into the postsynaptic cell before and immediately after the stimulation protocol did not modify the cells' membrane input resistance $(97.3 \pm 1.2 \%$ of control after the train, $p>0.05, n=18$, data not shown). This suggests that a change in membrane conductance did not account for the decrease in the amplitude of the synaptic responses observed. Moreover, FSI was not affected by the application of a $\mathrm{GABA}_{\mathrm{B}}$ receptor antagonist (CGP35348, $50 \mu \mathrm{M}, p>0.5, n=4$, data not shown). This indicates that, although presynaptic $\mathrm{GABA}_{\mathrm{B}}$ receptors tightly control axonal GABA release from NGFCs (Price et al., 2005, 2008), GABA $_{\mathrm{B}}$ receptor activation is not involved in FSI.

In summary, in vivo NGFC firing during hippocampal theta rhythm induces a DSI-like event, we termed FSI. In the next 
A

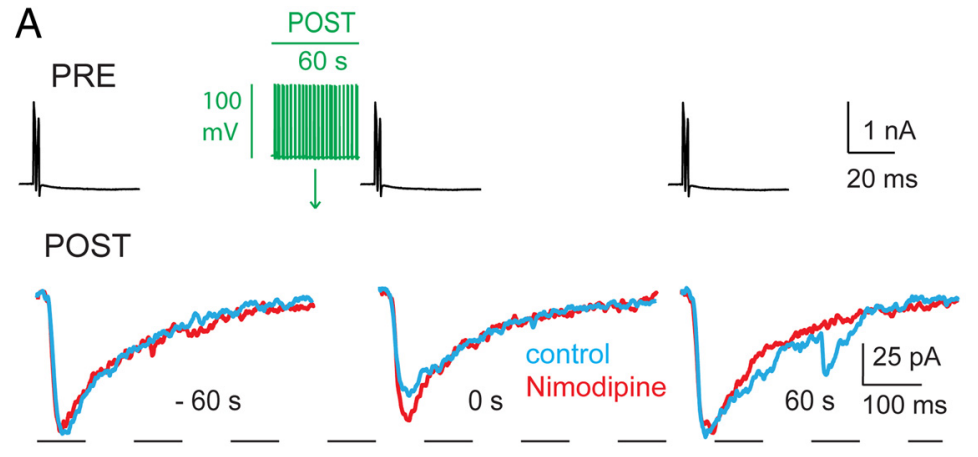

B

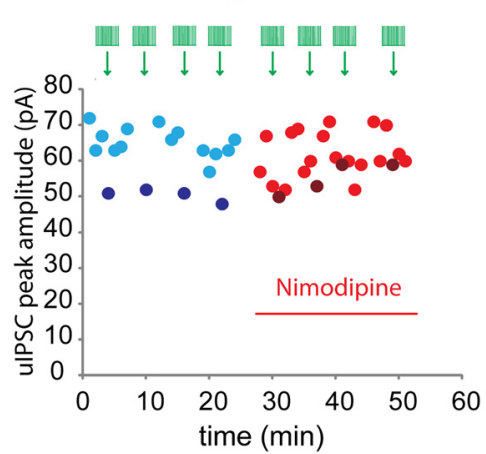

C

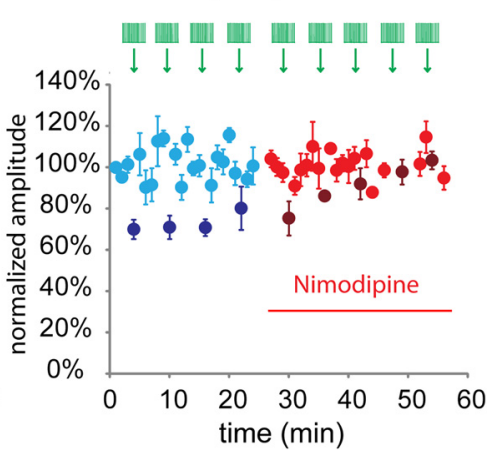

Figure 4. The L-type $\mathrm{Ca}^{2+}$ blocker nimodipine inhibits FSI. A, Presynaptic action currents (PRE, black traces) evoked inward uIPSCs in a postsynaptic NGFC recorded with an electrode filled with $84 \mathrm{~mm} \mathrm{Cl}^{-}$solution (POST, blue traces). Injection of the stimulation protocol in the postsynaptic cell induced a transient depression of the uIPSC amplitude (middle, blue trace), that returned to control level $60 \mathrm{~s}$ after the end of the stimulation protocol (right, blue trace). Application of the L-type $\mathrm{Ca}^{2+}$ channel blocker nimodipine (10 $\mu \mathrm{m}$ ) inhibited FSI (red traces). B, quantification of the ulPSC peak amplitude that occurred before or during the bath application of nimodipine for the data shown in $\boldsymbol{A}$ (dark symbols denote values immediately after stimulation protocol). C, Normalized data (mean and SEM) for all uIPSCs studied with this protocol (FSI control was $70.6 \pm 4.8 \%$ and $94.8 \pm 6.3 \%$ with nimodipine, $p<0.01, n=5)$.

experiments, we sought to determine the mechanisms involved in this phenomenon.

\section{What triggers FSI in the postsynaptic neuron?}

FSI was initiated by the postsynaptic neuron firing, suggesting that an active process occurring in the dendrites was likely to be involved. According to this idea, AP back-propagation (bAP) should occur along the postsynaptic dendrites to trigger this event. To test this hypothesis, we visualized bAPs in 24 interneurons of the SLM by using single cell voltage imaging as described in the Materials and Methods (Fig. 2A). We analyzed $\Delta F / F$ signals at various dendritic locations associated with a somatic AP evoked by intracellular current injection. The cells tested with this protocol included NGFCs $(n=9)$, but also other interneurons of the SLM such as putative perforant path associated and CCK-expressing basket cells $(n=15)$. We observed a $\Delta F / F$ signal with an AP shape at all dendritic locations and in all interneurons studied. Because the amount of dye distributed along the dendritic axis may vary, to quantify the signal we performed a calibration protocol of $\Delta F / F$ signals using injection of longlasting hyperpolarizing current pulses into the soma as described in the Materials and Methods. The calibration procedure is shown in Figure $2 B$. Using this procedure, we observed robust bAPs along the dendrites of NGFCs and other hippocampal interneurons of the SLM without any significant decrement $(p>$ $0.5, n=24)$. A summary of the quantification of the bAP along

the dendrites of all interneurons studied with VSD is shown in Figure 2C. Optically recorded bAP events were always associated with somatic APs, and both signals were abolished by the application of tetrodotoxin (TTX, $1 \mu \mathrm{M}$; Fig. 2D). Thus, APs back-propagated along the dendrites of NGFCs and other interneurons of the SLM, and this event is likely to initiate FSI.

In the next series of experiments, we tested the hypothesis that the postsynaptic bAPs elicited an increase in the dendritic $\mathrm{Ca}^{2+}$ concentration. First, we injected the stimulation protocol to induce FSI, and then we applied subthreshold depolarizing current pulses $(75 \mathrm{pA} \times 1 \mathrm{~ms})$ with the same temporal pattern of the in vivo action potentials. This protocol was unable to induce FSI in all cell pairs tested ( $97.4 \pm$ $2.5 \%$ of control, $p>0.5, n=11$; Fig. 3 ), consistent with the voltage imaging data. Second, postsynaptic neurons were recorded with a solution containing the $\mathrm{Ca}^{2+}$ chelator BAPTA (10 mM). In these experiments, only pairs showing FSI immediately after the formation of wholecell patch-clamp recording were tested. Under this condition, FSI was progressively attenuated (FSI was $69.7 \pm 4.6 \%$ of control at the onset of the recording and $86.7 \pm 3.0 \%$ of control after $8 \pm 2 \mathrm{~min}$., $p<0.05, n=4$ ), consistent with the delayed action of BAPTA at the distal dendritic sites of the recorded interneurons. Third, we investigated the source of dendritic $\mathrm{Ca}^{2+}$ leading to FSI. To test the involvement of intracellular $\mathrm{Ca}^{2+}$ stores (Collin et al., 2005), we inserted ryanodine $(200 \mu \mathrm{m})$ and $\mathrm{U} 73122(3 \mu \mathrm{m})$ into the patch pipette recording from postsynaptic cells to inhibit $\mathrm{Ca}^{2+}$ release from the endoplasmic reticulum and phospholipase $\mathrm{C}$, an important component of the $\mathrm{Ca}^{2+}$ signaling cascade, respectively. However, the diffusion of these blockers in the postsynaptic cell did not alter FSI, which was initially $83.5 \pm 6.2 \%$ of baseline and $78.9 \pm 7.4 \%$ after $18 \mathrm{~min}$ of recording $(p>0.1, n=3$, data not shown). This result rules out that the endoplasmic reticulum is a relevant source of $\mathrm{Ca}^{2+}$ for FSI induction. As a positive control, we observed that the insertion of ryanodine $(200 \mu \mathrm{m})$ and U73122 $(3 \mu \mathrm{m})$ in the presynaptic cell gradually inhibited the uIPSCs in experiments lasting $\sim 20 \mathrm{~min}$. (data not shown).

Alternatively, $\mathrm{Ca}^{2+}$ entry through dendritic L-type $\mathrm{Ca}^{2+}$ channels could trigger FSI, consistent with their involvement on short-term plasticity, but not on baseline GABAergic transmission (Jensen and Mody, 2001). In all neurons tested, bath applied nimodipine $(10 \mu \mathrm{m})$ inhibited FSI without affecting the size of uIPSCs evoked by low frequency of stimulation. Quantitatively, FSI was $70.6 \pm 4.8 \%$ of control at the onset of the recording and $94.8 \pm 6.3 \%$ of control after 20 min. of nimodipine application $(p<0.01, n=5$; Fig. 4$)$.

Together, these results suggest that L-type $\mathrm{Ca}^{2+}$ channels, but not ryanodine-sensitive $\mathrm{Ca}^{2+}$ stores, are involved in FSI induction.

Next, to directly measure $\mathrm{Ca}^{2+}$ signals associated with the stimulation firing protocol, we performed $\mathrm{Ca}^{2+}$ imaging experiments of NGFC dendrites using the low-affinity indicator OG5N 
$(0.5 \mathrm{~mm})$ to minimize the physiological perturbation of the $\mathrm{Ca}^{2+}$ homeostasis. First, we measured the dendritic $\mathrm{Ca}^{2+}$ signal associated with a single AP (Fig. 5A) and with a train of 10 APs at $100 \mathrm{~Hz}$ (Fig. 5B). As shown in Figure 5, the $\mathrm{Ca}^{2+}$ transient associated with the AP train had a slower decay time compared with that associated with a single AP. Then, we measured the $\mathrm{Ca}^{2+}$ signal associated with the stimulation protocol and compared it with the linear sum of a single AP response template. As expected from the previous series of experiments, the $\mathrm{Ca}^{2+}$ signal associated with the stimulation protocol was larger than that obtained by summation of template signals. Crucially, this supralinear $\mathrm{Ca}^{2+}$ summation, as quantified by the difference of the $\mathrm{Ca}^{2+}$ signal at the end and $10 \mathrm{~s}$ after the onset of the stimulation protocol, was significantly larger in the postsynaptic neurons showing FSI than in the postsynaptic cells that did not display FSI (Fig. $5 C, D ; n=6$ each group, $p<0.05$ ). To estimate the change in dendritic-free $\mathrm{Ca}^{2+}$ concentration associated with an action potential and with the stimulation protocol we performed a series of calibration experiments using both OG5N and MF2 in the pipette. Comparison of $\Delta F / F$ signals associated with three different stimulation protocols $(5,10$, or 20 APs at $100 \mathrm{~Hz}$ ) gave a conversion factor of $\sim 2.5$ for OG5N (Fig. $5 E$ ) indicating that $\Delta F /$ $F=1 \%$ corresponded approximately to a free $\mathrm{Ca}^{2+}$ concentration change of $100 \mathrm{nM}$ for this indicator, assuming a $K_{\mathrm{d}}=25 \mu \mathrm{M}$ for MF2 (Cueni et al., 2008). We conclude that a sustained elevation of free $\mathrm{Ca}^{2+}$ in the dendrites of the postsynaptic neuron (typically $>1 \mu \mathrm{M}$ ) is associated with the stimulation protocol that induces FSI. Such prolonged increase in dendritic $\mathrm{Ca}^{2+}$ could lead to the release of a chemical messenger.

\section{What messenger(s) is responsible for FSI?}

What messenger triggers FSI? The nNOS is expressed by several hippocampal interneurons including NGFCs (Price et al., 2005; Tricoire et al., 2010; Tricoire and Vitalis, 2012). Furthermore, the NOsensitive guanylyl cyclase (NO-sGC) receptor has been detected in the axon terminals and in the soma-dendritic compartment of various types of hippocampal interneurons (Szabadits et al., 2007). Both signals are highly enriched in the SLM of the hippocampus (Szabadits et al., 2007). Therefore, NO could be released from the dendrites of NGFCs and some other interneuron types of the SLM, diffuse retrogradely, and inhibit the release of GABA
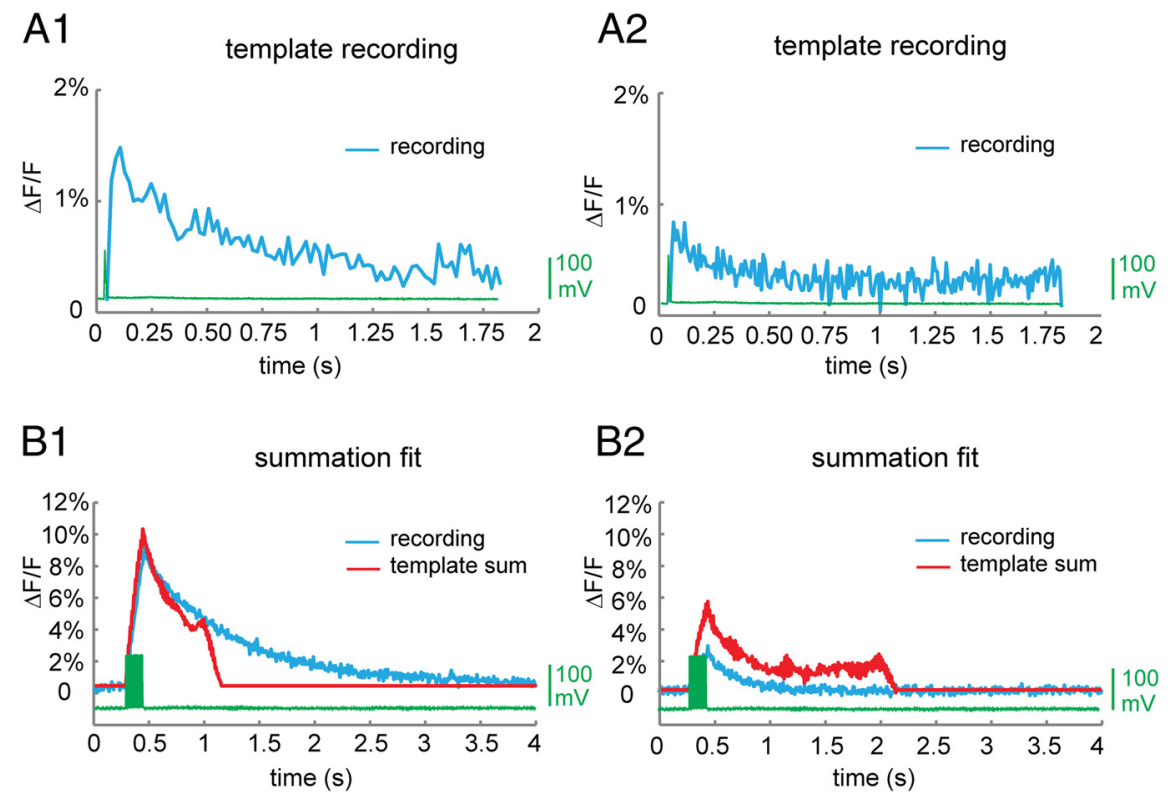

\section{C1}

protocol fit

\section{$\mathrm{C} 2$}
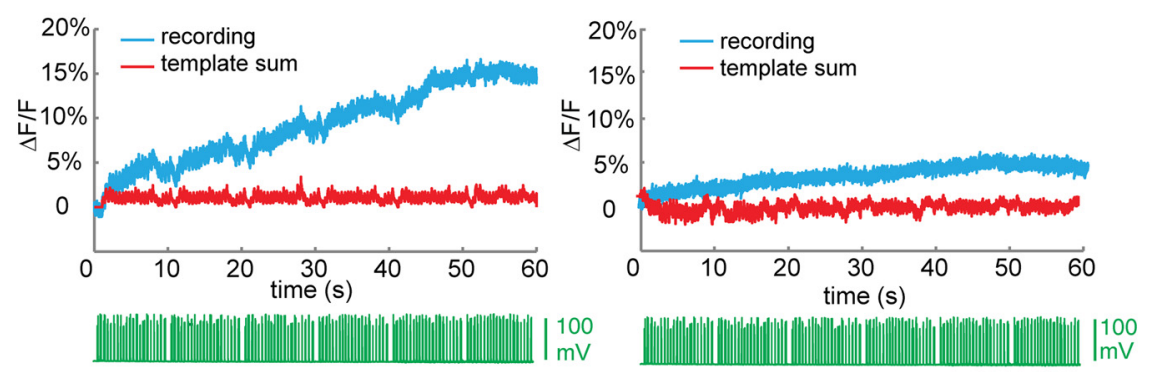

$\mathrm{D}$

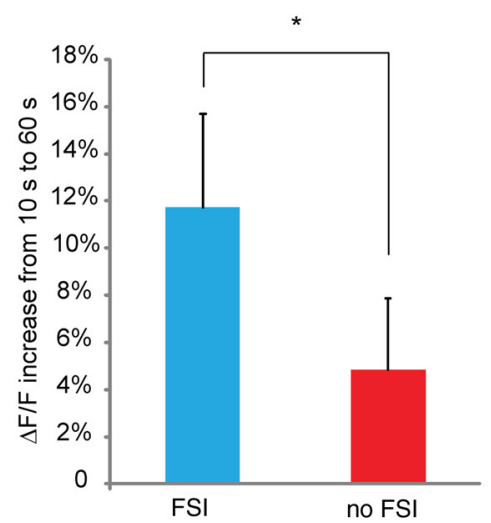

E

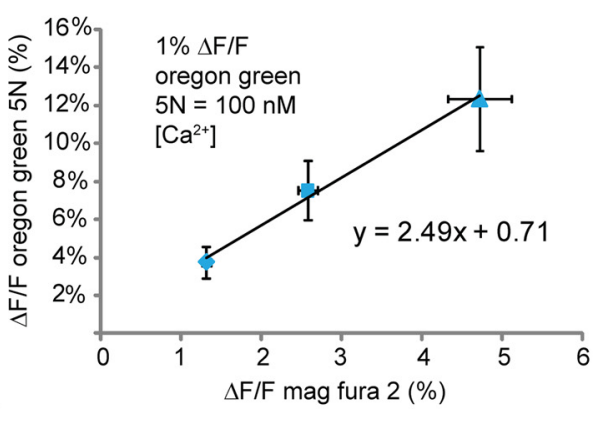

Figure 5. Sustained elevation of $\mathrm{Ca}^{2+}$ in the dendrites of postsynaptic interneurons triggers $\mathrm{FSI} . A, \Delta F / F \mathrm{Ca}^{2+}$ signal from an NGFC with FSI (A1) or without FSI (A2) filled with $0 G 5 N$ (blue trace) associated with an AP (green trace, single trial). $\boldsymbol{B}$, Same as $\boldsymbol{A}$ (in the same neurons) but for a train of $10 \mathrm{APs}$ at $100 \mathrm{~Hz}$ (single trial); note the increased decay time compared with the calcium signal associated with single AP; the red trace is the summation of 10 template $\Delta F / F \mathrm{Ca}^{2+}$ signals associated with the single AP (note the faster decay time). C, $\Delta F / F \mathrm{Ca}^{2+}$ signals (blue traces) associated with the stimulation protocol (green traces, single trial) from the dendrites of two NGFC cells, one exhibiting FSI (C1) and the other not showing $\mathrm{FSI}(\mathrm{C2})$; the red traces are again the linear summation of single AP template $\triangle F / F \mathrm{Ca}^{2+}$ signals; note the larger supralinear summation of $\triangle F / F \mathrm{Ca}^{2+}$ signals in the cell exhibiting FSI. D, Columns and error bars are the mean and the SEM of the difference of $\Delta F / F$ dendritic $\mathrm{Ca}^{2+}$ signal occurring 60 and $10 \mathrm{~s}$ after the onset of the stimulation protocols in postsynaptic neurons with FSI (blue column) and in cells without FSI (red column); this value in the two populations of neurons was significantly different $(n=6, p<0.05)$. $E$, Calibration of $0 \mathrm{G} 5 \mathrm{~N} \Delta F / F \mathrm{Ca}^{2+}$ signal in terms of MF2 $\Delta F / F \mathrm{Ca}^{2+}$ signal: plot of $0 G 5 \mathrm{~N} \Delta F / F$ peak versus MF2 $\Delta F / F$ peak associated with different protocols (spade, $5 \mathrm{APs}$ at $100 \mathrm{~Hz}$; square, $10 \mathrm{APs}$ at $100 \mathrm{~Hz}$; triangle, $20 \mathrm{APs}$ at $100 \mathrm{~Hz}, n=6$ ) in the same cells. The linear fit gives a conversion factor of 2.5; given that $1 \%$ for MF2 corresponds to $\sim 250 \mathrm{~nm}, 1 \%$ for $0 \mathrm{G} 5 \mathrm{~N}$ corresponds to $\sim 100 \mathrm{~nm}$. 

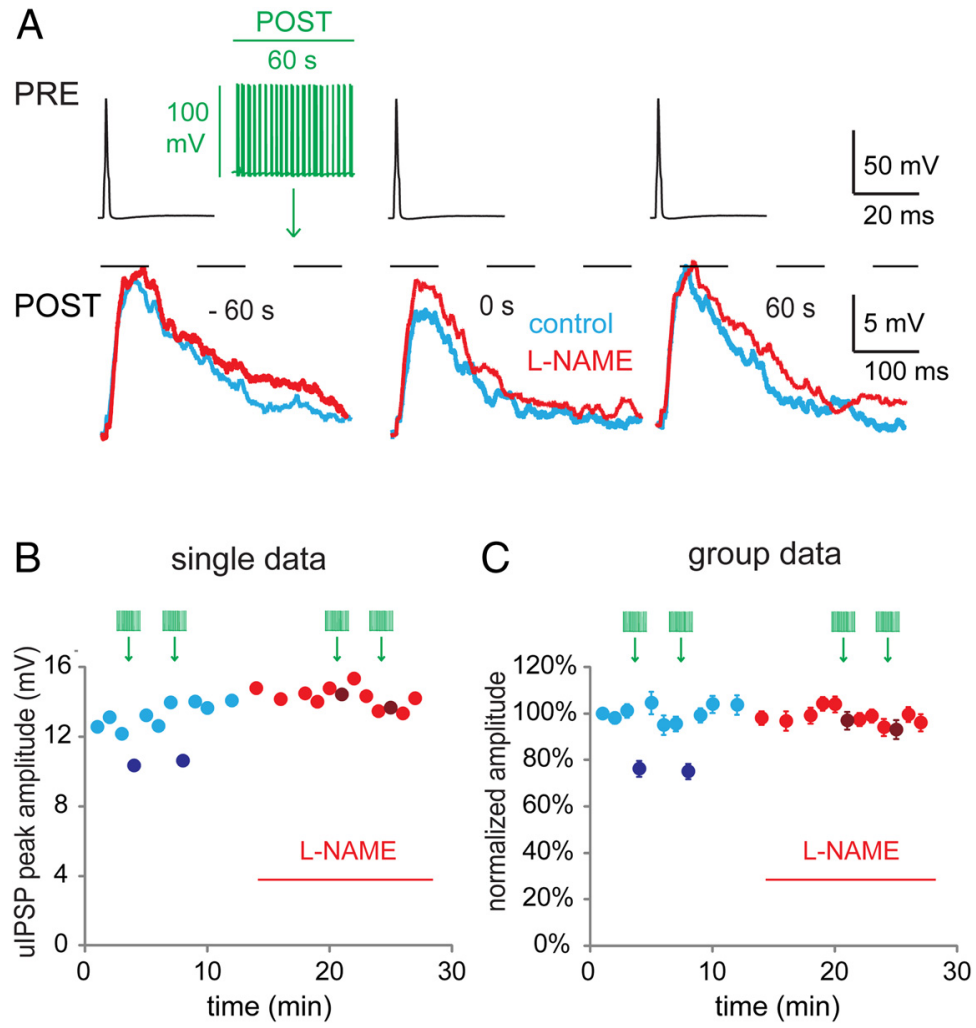

Figure 6. ThenNOS inhibitor L-NAMEblocks FSI. A, Presynaptic APs (PRE, black traces) elicited depolarizing ulPSPs (control, left traces superimposed) recorded with an electrode filled with $84 \mathrm{mM} \mathrm{Cl}^{-}$solution showing FSI immediately after stimulation protocol applied to a postsynaptic NGFC (control, middle, blue trace). The uIPSP recovered 60 s after the stimulation protocol (right, blue trace). Application of the nNOS inhibitor L-NAME (200 $\mu$ m) blocked FSI (red traces). B, Quantification of the uIPSP peak amplitude that occurred before or after the stimulation protocol (dark symbols) in control and in the presence of L-NAME for the data shown in $A$. C, Normalized data (mean and SEM, shaded areas) for all ulPSPs or ulPSCS studied with this protocol (FSI control was $76.6 \pm 2.5 \%$ and $95.1 \pm 2.4 \%$ with L-NAME, $p<0.001, n=10$ ).

from other interneurons. We tested this hypothesis by studying the action of the nNOS inhibitor L-NAME $(200 \mu \mathrm{M})$ on FSI. We first injected the stimulation protocol in a postsynaptic neuron to induce FSI $(76.7 \pm 2.5 \%, p<0.001, n=11)$. Next, we applied the nNOS inhibitor L-NAME $(200 \mu \mathrm{M})$ for at least $10 \mathrm{~min}$ and the stimulation protocol was repeated. Strikingly, we found that L-NAME abolished FSI (95.1 $\pm 2.4 \%, p<0.001, n=10 / 11$; Fig. 6). It is worth noting that we found no significant effect of $200 \mu \mathrm{M}$ L-NAME on spontaneous (s)IPSCs (in the presence of $3 \mathrm{~mm}$ kynurenic acid to block sEPSCs, $n=3$, data not shown). Both amplitude and inter-event distributions of sIPSCs were not significantly different in control and in the presence of L-NAME ( $p>0.1$ Kolmogorov-Smirnov test for each cell). This result suggests that the intracellular NO level is low under baseline conditions. Moreover, L-NAME did not affect the peak amplitude or the kinetics of single VSD-recorded bAP elicited $125 \mathrm{~ms}$ after $60 \mathrm{~s}$ stimulation firing $(n=10)$. The bAP peak amplitude and the half-width was not changed by L-NAME $(p>0.1, n=10$, data not shown), further indicating that NO is released downstream of the APs back-propagating along the dendrites of the interneurons.

Further experiments confirmed the involvement of $\mathrm{NO}$ as a signal mediating FSI. First, we investigated whether blocking the NO-sGC receptor, the main effector of NO, abolished FSI. Similar to the nNOS inhibitor, bath application of ODQ $(10 \mu \mathrm{M})$, a NO-sGC receptor antagonist, applied for at least $10 \mathrm{~min}$, blocked FSI that was successfully induced before the application of the drug in each cell tested (Fig. 7; FSI control was $71.1 \pm 3.7 \%$ and during ODQ was $96.8 \pm 2.3 \%, p<0.01$, $n=8)$. Second, the application of the NO precursor L-arginine ( $1 \mathrm{~mm}, n=5$; Palmer et al., 1988) potentiated FSI (FSI control was $73.1 \pm 4.4 \%$ and during L-arginine was $62.4 \pm 6.1 \%, p<0.05, n=5$, data not shown). Third, the application of the NO donor SNP $(200 \mu \mathrm{M})$ occluded FSI, consistent with the idea that this agent would saturate $\mathrm{NO}$ receptors and with the action of this drug on NO-mediated modulation of excitatory synaptic events (Makara et al., 2007). FSI was $72.4 \pm 5.6 \%$ before and $96.5 \pm 6.3 \%$ in the presence of SNP, $n=6$, $p<0.05$, data not shown). Fourth, L-NAME blocked FSI in the presence of the cannabinoid receptor $1\left(\mathrm{CB}_{1}\right)$ antagonist AM-251 (data not shown, FSI was $74.1 \pm 6.1 \%$ in control, $77.9 \pm 5.3 \%$ in the presence of AM-251, $p>0.05$, and $97.4 \pm$ $3.9 \%$ after addition of L-NAME, $p<0.05$, $n=3)$. Finally, the likelihood of FSI detection was enhanced when synaptically coupled pairs of tdTomato-labeled nNOS neurons were recorded in an nNOS-CretdTomato mouse line (Fig. $8 A-D$ ). In these Experiments 7 of 9 cell pairs tested showed a robust FSI $(69.4 \pm 2.6 \%, p<$ $0.001)$ induced by the stimulation protocol. This frequency of occurrence of FSI was significantly higher than the probability of FSI occurrence in pairs recorded from control rats (78 vs 39\% FSI detection, $p<0.01, \chi^{2}$ test; Fig. $\left.8 D\right)$. The FSI observed when recording from tdTomato-labeled nNOS neurons was blocked by $200 \mu \mathrm{M}$ L-NAME or $10 \mu \mathrm{M}$ ODQ $(n=3$, data not shown). Control analysis showed that the nNOS-CreER driver correctly labeled nNOS-positive neurons. To this end, three tdTomato mice $(n=3)$ have been perfused, their brain fixed and tested for a specific antibody against nNOS. The great majority of tdTomato-expressing hippocampal neurons from these mice were immunolabeled for nNOS (98 of 104 of counted cells; Fig. 8 E,F).

Together, our data suggest that NO is the signal responsible for FSI. It is likely that NO is released from the dendrites of NGFCs, diffuses retrogradely, binds to specific presynaptic receptors, and inhibits the release of GABA from other NGFCs.

\section{Physiological implications of FSI}

To test the physiological role of FSI on single-cell integration, we recorded putative unitary EPSPs in NGFCs evoked by the minimal stimulation of the SLM at gamma frequency in the presence of $5 \mu \mathrm{M}$ gabazine and $50 \mu \mathrm{M}$ CGP35348 to block synaptic inhibition. This stimulation evoked short-term EPSP facilitation followed by depression, as we have previously reported (Price et al., 2005). Of note, the stimulation protocol (in vivo firing pattern) did not evoke any significant change in the amplitude of these EPSPs, excluding a retrograde modulation of excitatory synapses (the EPSPs immediately after the firing protocol were $95.8 \pm$ $7.0 \%$ of control, $p>0.5, n=3$, data not shown). Next, we injected a train of EPSPs as synaptic conductance by using dynamic clamp (dEPSPs) in postsynaptic NGFCs (Fig. 9). Because 
NGFCs have short dendrites and are biophysically compact, the somatic injection of unitary dEPSPs should represent a realistic representation of EPSPs evoked by stimulation of one or a few fibers present in the SLM, such as the perforant path from the entorhinal cortex. Coincident with dEPSPs injection, an action potential in a presynaptic NGFC was also evoked, and this elicited a hyperpolarizing UIPSP in the postsynaptic NGFC. Next, the stimulation protocol (in vivo firing pattern) was applied to the postsynaptic NGFC to induce FSI and transiently reduce the size of the UIPSP $(69.4 \pm 10.6 \%$ of control, $p<0.05, n=8)$. We observed that when FSI occurred, the amplitude of the dEPSPs was significantly increased (Fig. 9; $p<$ 0.05 for the first three dEPSPs of the train, $n=8$ ) compared with dEPSPs elicited in the presence of control synaptic inhibition before or after FSI. Remarkably, this affected several sequential dEPSPs, consistent with the long-lasting duration of NGFC-evoked uIPSPs (Tamás et al., 2003; Price et al., 2005). Thus, FSI transiently increased the size of the dEPSPs thereby promoting the temporal/spatial integration of the uEPSPs elicited by stimulation of perforant path/other excitatory fibers present in the SLM.

\section{Discussion}

The data suggest novel physiological roles for the rhythmic firing of hippocampal NGFCs during theta oscillations and for the presence of NO in this interneuron type. We report that $\mathrm{NO}$ acts as a transmitter, released by the dendrites and likely acting at presynaptic site, to modulate the strength of local inhibitory circuits, an event we called FSI. We also show that FSI transiently modifies the strength of incoming EPSPs onto interneurons.

The FSI plastic event reported here resembles the classical DSI phenomenon consisting of postsynaptic depolarization-induced suppression of synaptic inhibition (Alger, 2012). However we triggered FSI by the injection of a firing sequence recorded in vivo during theta oscillations (Fuentealba et al., 2010) and replayed in the same cell type in vitro. In contrast, DSI is usually triggered by a prolonged steady depolarization of the postsynaptic neuron (Regehr et al., 2009; cf. Dubruc et al., 2013). We used an in vivo firing sequence during theta oscillations because this rhythm is physiologically relevant and it is prominent in the SLM (Buzsáki, 2002). The firing of NGFCs may have an important role in this rhythm and it may link phasic dipoles impinging on CA1 pyramidal cells. Specifically, NGFCs provide simultaneous inhibition to pyramidal neurons and interneurons (Price et al., 2005, 2008); NGFC firing is time-locked to the peak of the theta cycle coincident with the synaptic volley from the entorhinal cortex (Fuentealba et al., 2010), and it evokes uIPSCs with duration close to a single theta cycle (Capogna and Pearce, 2011). Firing sequences shorter than $60 \mathrm{~s}(10-30 \mathrm{~s})$ produced less robust and reliable FSI (data not shown). However, we have not systematically addressed the issue of the optimal firing duration needed to induce FSI.
Because FSI is evoked by the firing of the postsynaptic neuron, the next step has been to test whether bAPs were present in these neurons. We studied this issue by recording bAPs with voltage imaging at different dendritic sites (range, 20-120 $\mu \mathrm{m}$ from the soma). We found that bAPs were present in all interneurons of the SLM tested and was particularly robust in NGFCs. The bAPs were also detected in the dendrites after the injection of the in vivo firing used as stimulation protocol to induce FSI, suggesting a faithful propagation of the signal during physiologically relevant firing. Previous data obtained by using $\mathrm{Ca}^{2+}$ imaging or dual dendritic and somatic patch-clamp recording of hippocampal or cortical interneurons reported significant attenuation of bAPs with distance from the soma because of the higher density of $\mathrm{K}^{+}$ channels in distal dendrites (Goldberg et al., 2003; Aponte et al., 2008; Topolnik et al., 2009; Hu et al., 2010; Evstratova et al., 2011). Other studies reported more robust bAPs in dendrites of interneurons by using $\mathrm{Ca}^{2+}$ (Rozsa et al., 2004) or voltage imaging (Casale and McCormick, 2011). The notion that emerges from the present and previous studies is of neuron type-specific attenuation of bAPs along the dendrites of various interneuron types. Importantly, we observed that the L-type $\mathrm{Ca}^{2+}$ channels, but not $\mathrm{Ca}^{2+}$ stores, mediate FSI induction. Because baseline uIPSCs were not affected by an L-type $\mathrm{Ca}^{2+}$ channel antagonist, it is likely that $\mathrm{Ca}^{2+}$ influx through dendritic channels is involved in this effect. Thus, as for release of GABA at hippocampal synapses (Jensen and Mody, 2001), our data suggest that L-type $\mathrm{Ca}^{2+}$ channels are use-dependent. Our results are consistent with the finding that L-type $\mathrm{Ca}^{2+}$ channels, in addition to N-type $\mathrm{Ca}^{2+}$ channels, initiate DSI (Lenz et al., 1998). Interestingly, 
A

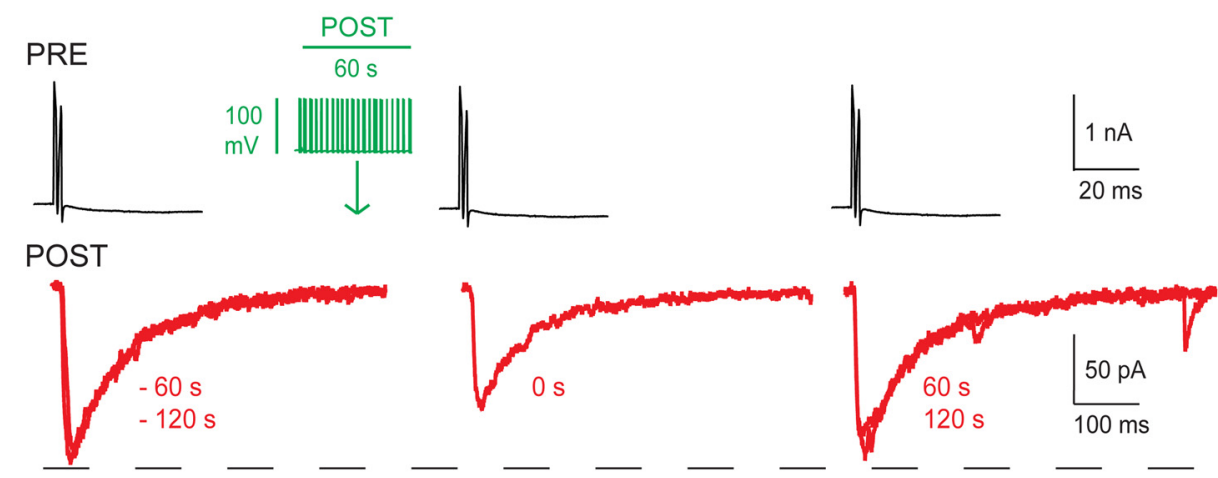

B

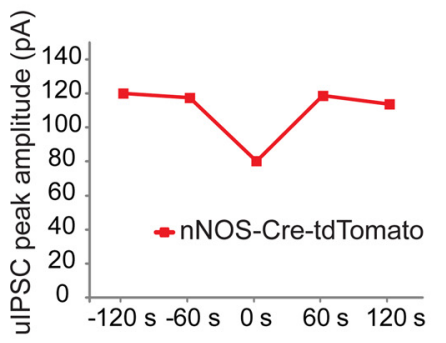

C

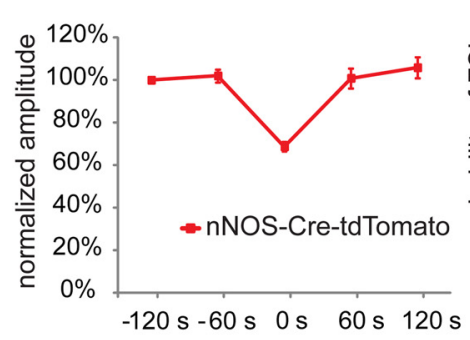

D

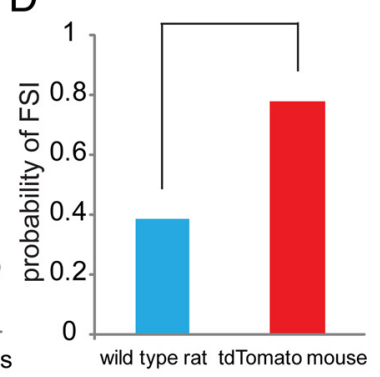

$E$

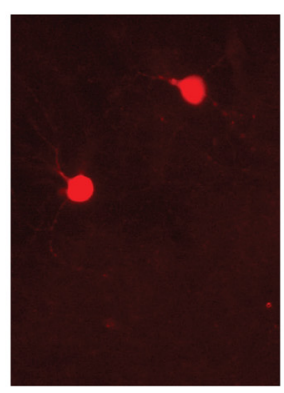

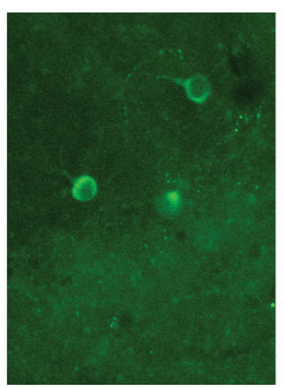

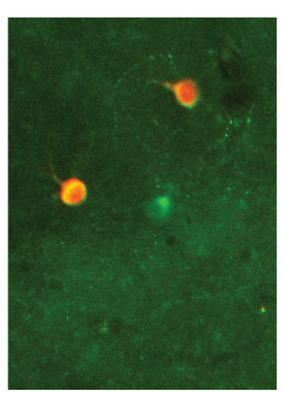

$\mathrm{F}$

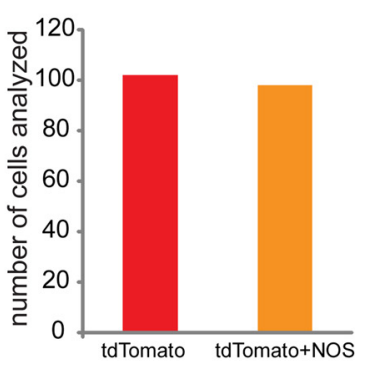

Figure 8. FSI occurs frequently in pairs of neurons expressing nNOS-Cre-tdTomato. A, NGFC paired recording, voltage-clamp mode, a presynaptic action current (PRE, black trace) evoked an inward uIPSC in a postsynaptic NGFC recorded with an electrode filled with $84 \mathrm{~mm} \mathrm{Cl}^{-}$solution (POST, red traces superimposed). Injection of the stimulation protocol in the postsynaptic cell induced a transient depression of the uIPSC amplitude (middle trace), that returned to control level 60 and $120 \mathrm{~s}$ after the stimulation protocol (right, superimposed traces). $\boldsymbol{B}$, ulPSC mean peak amplitude before and after the stimulation protocol for the data shown in $A$. C, Summary of mean and SEM peak amplitudes of uIPSCs before and after the stimulation protocol in all pairs recorded (FSI $=$ $69.4 \pm 2.6 \%, p<0.001, n=7)$. D, Bar graphs that the probability to observe FSI was significantly higher when pairs of tdTomato neurons were recorded compared with pairs recorded in wild-type rats (78vs 39\% FSI detection, $p<0.01, \chi^{2}$ test). E, Examples of two tdTomato-expressing neurons of the hippocampal SLM (left), also-immunopositive for nNOS (middle); a merged picture is shown on the right. An nNOS immunopositive cell not expressing tdTomato is also visible. $\boldsymbol{F}$, Summary data, 98 of 104 tdTomato-expressing neurons also expressed nNOS.

when we monitored dendritic $\mathrm{Ca}^{2+}$ levels during the stimulation protocol used to induce FSI, we found an excellent correlation between the presence of FSI and supralinear $\mathrm{Ca}^{2+}$ signal. This result suggests that bAP-dependent rise of $\mathrm{Ca}^{2+}$ is required to trigger the release of retrograde signal(s) mediating FSI. The mechanisms underlying such differences in dendritic $\mathrm{Ca}^{2+}$ levels observed in our study remain unknown. Several factors could be involved, such as heterogeneous $\mathrm{Ca}^{2+}$ buffering properties, various $\mathrm{Ca}^{2+}$ extrusion rate, or variable distribution of dendritic $\mathrm{Ca}^{2+}$ channel type/concentration among different neurons studied.

Next, we identified NO as the signal mediating FSI. Our data are consistent with the idea that the prolonged physiological firing of the postsynaptic cell leads to $\mathrm{Ca}^{2+}$-dependent release of NO from dendrites, which activates presynaptic NO-sGC receptors, which in turn, depresses GABA release from axon terminals.
Our pharmacological results clearly involved NO as a signal mediating FSI: the nonspecific nNOS inhibitor L-NAME blocked FSI in virtually all cell pairs tested, the specific NO-sGC receptor blocker ODQ abolished FSI in all cell pairs tested, the NO precursor L-arginine potentiated FSI, and the NO donor SNP occluded FSI. Furthermore, pairs of tdTomato-nNOS-expressing neurons displayed a significantly higher frequency of FSI occurrence compared with randomly recorded pairs. A dendritic release of NO is consistent with its gaseous nature that does not require vesicles for its release (Garthwaite, 2008). It is important to note that our data cannot firmly exclude a purely postsynaptic mechanism, although the kinetics of UIPSCs during FSI was indistinguishable from that of control uIPSCs, a result that makes a postsynaptic modulation of the $\mathrm{GABA}_{\mathrm{A}}$ receptor unlikely. Additional functional tests to investigate presynaptic versus postsynaptic mechanisms (such as the CV analysis of the synaptic 
A
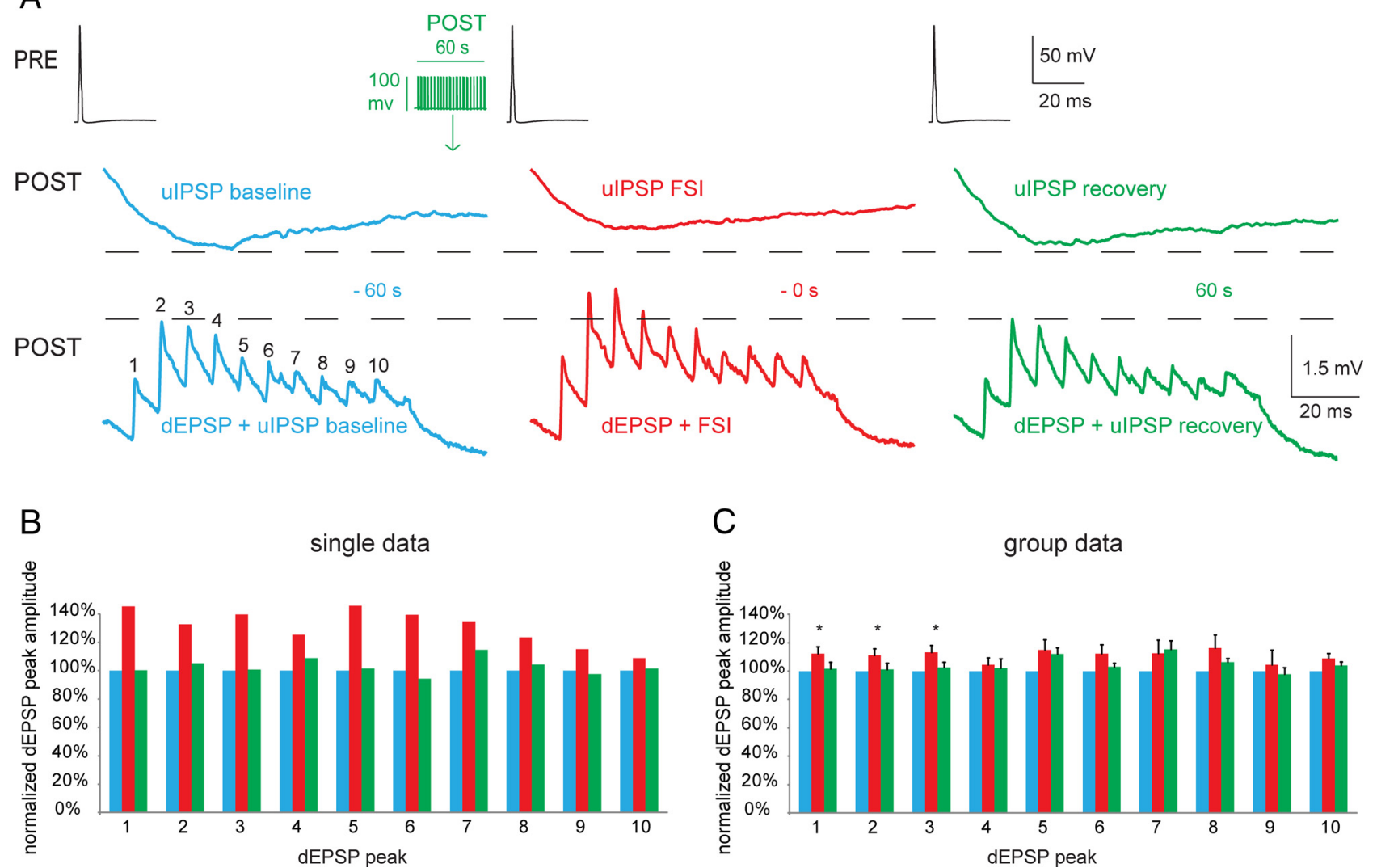

Figure 9. FSI transiently modulates EPSPs impinging onto NGFCs. A, An EPSP train was injected as synaptic conductance using dynamic clamp (POST, dEPSPs, blue trace, - 60 s) in a postsynaptic NGFC, whereas an action potential in a presynaptic NGFC (PRE, black trace) elicited a coincident uIPSP. Application of the stimulation protocol in the postsynaptic cell evoked a transient, smaller ulPSP (FSI). As a result, a significant enhanced depolarization level was reached by several dEPSPs of the train (red trace), the depolarization level of the EPSPs returned to the baseline $60 \mathrm{~s}$ after FSI (green trace, 60 s). $\boldsymbol{B}$, C, Normalized values of the dEPSPs amplitude during FSI (red bars) or $60 \mathrm{~s}$ after FSI (recovery, green bars) versus before FSI (blue histograms), for the events shown above ( $\boldsymbol{B}$ ) or for all recorded cell pairs (C). In the presence of FSI, the first three dEPSPs had significantly larger amplitude than before FSI $(p<0.05, n=8)$.

responses) were precluded by the need of collecting tens of uIPSCs to perform this analysis. This would have required unrealistic long-lasting recordings due to the well known requirement of low-frequency stimulation to evoke stable NGFC-mediated IPSCs (Tamás et al., 2003; Price et al., 2005). Our results are consistent with data showing high expression of the NO-sGC receptor in the SLM, and with the detection of the molecular machinery for retrograde NO signaling, such as NOs in hippocampal interneurons (Szabadits et al., 2007) in addition to CA1 pyramidal cells (Burette et al., 2002). Functionally, it has been reported that NO released from CA1 pyramidal cell retrogradely mediates DSI (Makara et al., 2007). However, this effect by $\mathrm{NO}$ was only observed after prior activation of the muscarinic acetylcholine receptor, and it was triggered by the steady depolarization of the postsynaptic neuron (Makara et al., 2007).

The evidence that NO is a retrograde signal released from postsynaptic GABAergic neurons to transiently depress synaptic inhibition is unprecedented, to our knowledge. An endocannabinoid is the classical retrograde mediator of DSI, including synaptic connections between hippocampal interneuron-principal cell (Ohno-Shosaku et al., 2001; Wilson and Nicoll, 2001), hippocampal radiatum CCK-expressing interneurons (Ali, 2007), and it also mediates the self-induced hyperpolarization of lowthreshold spiking dendrite-targeting cortical interneurons (Bacci et al., 2004).

What cell types of the hippocampal SLM are involved in FSI? The great majority of anatomically identified recorded pairs ex- hibiting FSI were identified as NGFCs. This cell type expresses nNOS together with several other nonspecific markers in the rodent hippocampus (Price et al., 2005; Fuentealba et al., 2010). Fate-mapping analysis shows that hippocampal NGFCs derived from the median ganglionic eminence express nNOS, whereas NGFCs originating in the caudal ganglionic eminence are nNOSnegative (Tricoire et al., 2010; Tricoire and Vitalis, 2012). Our data demonstrate a selective influence of nNOS-expressing NGFCs on local synaptic activity. Moreover, a small percentage of pairs displaying FSI were likely to be perforant path-associated or CCK basket interneurons. This latter interneuron type is well known to express the $\mathrm{CB}_{1}$ receptor (Katona et al., 2001; Nyiri et al., 2005), but we previously observed that CCK frequently colocalizes with nNOS in a single-cell PCR analysis of SLM interneurons (Price et al., 2005). We cannot exclude that other types of interneurons of SLM, including Schaffer collateral associated cells, could also be involved in FSI, because of nonrecovery of some of our recorded cells or incomplete sampling.

It is important to note that FSI was detectable only in $\sim 40 \%$ of all synaptically coupled pairs recorded without any bias, and that this percentage rose to $\sim 80 \%$ when only nNOS-expressing interneurons of the SLM were tested. This finding agrees with the observations that some, but not all, NGFCs express nNOS (Tricoire et al., 2010) and that only a third of nNOS-expressing cells also express the NO-sGC receptor (Szabadits et al., 2007).

What is the functional role of FSI in the hippocampal networks? The SLM is an area of integration containing several 
excitatory inputs and local but also distant inhibitory inputs (Soltesz and Jones, 1995; Capogna, 2011; Melzer et al., 2012). Feedforward inhibition (Buzsáki, 1984; Pouille and Scanziani, 2001; Jarsky et al., 2005; Price et al., 2008) limits the temporal summation of EPSPs and generates a narrow "window of excitability" during which action potentials can occur in the postsynaptic neuron. We observed here that NGFC-mediated slow IPSPs modify the size of unitary EPSPs evoked by the stimulation of fibers present in the SLM, such as the perforant pathway. Crucially, this effect was transiently attenuated by coincident-occurring FSI. Furthermore, chains of interneurons are likely to coordinate the spatiotemporal organization of distinct but connected networks (Mizuseki et al., 2009; Chamberland and Topolnik, 2012). We speculate that FSI occurring in interneurons of the SLM transiently strengthens the rhythmic coordination between the entorhinal cortex and the CA1 area of the hippocampus.

\section{References}

Alger BE (2012) Endocannabinoids at the synapse a decade after the dies mirabilis (29 March 2001): what we still do not know. J Physiol 590:22032212. CrossRef Medline

Ali AB (2007) Presynaptic inhibition of GABAA receptor-mediated unitary IPSPs by cannabinoid receptors at synapses between CCK-positive interneurons in rat hippocampus. J Neurophysiol 98:861-869. CrossRef Medline

Aponte Y, Bischofberger J, Jonas P (2008) Efficient Ca2+ buffering in fast-spiking basket cells of rat hippocampus. J Physiol 586:2061-2075. CrossRef Medline

Bacci A, Huguenard JR, Prince DA (2004) Long-lasting self-inhibition of neocortical interneurons mediated by endocannabinoids. Nature 431: 312-316. CrossRef Medline

Baimbridge KG, Celio MR, Rogers JH (1992) Calcium-binding proteins in the nervous system. Trends Neurosci 15:303-308. CrossRef Medline

Burette A, Zabel U, Weinberg RJ, Schmidt HH, Valtschanoff JG (2002) Synaptic localization of nitric oxide synthase and soluble guanylyl cyclase in the hippocampus. J Neurosci 22:8961-8970. Medline

Buzsáki G (1984) Feed-forward inhibition in the hippocampal formation. Prog Neurobiol 22:131-153. CrossRef Medline

Buzsáki G (2002) Theta oscillations in the hippocampus. Neuron 33:325340. CrossRef Medline

Caillard O, Moreno H, Schwaller B, Llano I, Celio MR, Marty A (2000) Role of the calcium-binding protein parvalbumin in short-term synaptic plasticity. Proc Natl Acad Sci U S A 97:13372-13377. CrossRef Medline

Canepari M, Vogt KE (2008) Dendritic spike saturation of endogenous calcium buffer and induction of postsynaptic cerebellar LTP. PLoS One 3:e4011. CrossRef Medline

Canepari M, Vogt K, Zecevic D (2008) Combining voltage and calcium imaging from neuronal dendrites. Cell Mol Neurobiol 28:1079-1093. CrossRef Medline

Canepari M, Willadt S, Zecevic D, Vogt KE (2010) Imaging inhibitory synaptic potentials using voltage sensitive dyes. Biophys J 98:2032-2040. CrossRef Medline

Capogna M (2011) Neurogliaform cells and other interneurons of stratum lacunosum-moleculare gate entorhinal-hippocampal dialogue. J Physiol 589:1875-1883. CrossRef Medline

Capogna M, Pearce RA (2011) GABA A, slow: causes and consequences. Trends Neurosci 34:101-112. CrossRef Medline

Casale AE, McCormick DA (2011) Active action potential propagation but not initiation in thalamic interneuron dendrites. J Neurosci 31:1828918302. CrossRef Medline

Cauli B, Tong XK, Rancillac A, Serluca N, Lambolez B, Rossier J, Hamel E (2004) Cortical GABA interneurons in neurovascular coupling: relays for subcortical vasoactive pathways. J Neurosci 24:8940-8949. CrossRef Medline

Chamberland S, Topolnik L (2012) Inhibitory control of hippocampal inhibitory neurons. Front Neurosci 6:165. CrossRef Medline

Collin T, Marty A, Llano I (2005) Presynaptic calcium stores and synaptic transmission. Curr Opin Neurobiol 15:275-281. CrossRef Medline

Colmers WF, Klapstein GJ, Fournier A, St-Pierre S, Treherne KA (1991) Presynaptic inhibition by neuropeptide $\mathrm{Y}$ in rat hippocampal slice in vitro is mediated by a Y2 receptor. Br J Pharmacol 102:41-44. CrossRef Medline

Cossart R, Dinocourt C, Hirsch JC, Merchan-Perez A, De Felipe J, Ben-Ari Y, Esclapez M, Bernard C (2001) Dendritic but not somatic GABAergic inhibition is decreased in experimental epilepsy. Nat Neurosci 4:52-62. CrossRef Medline

Cueni L, Canepari M, Luján R, Emmenegger Y, Watanabe M, Bond CT, Franken P, Adelman JP, Lüthi A (2008) T-type Ca2+ channels, SK2 channels and SERCAs gate sleep-related oscillations in thalamic dendrites. Nat Neurosci 11:683-692. CrossRef Medline

Dubruc F, Dupret D, Caillard O (2013) Self-tuning of inhibition by endocannabinoids shapes spike-time precision in CA1 pyramidal neurons. J Neurophysiol 110:1930-1944. CrossRef Medline

Elfant D, Pál BZ, Emptage N, Capogna M (2008) Specific inhibitory synapses shift the balance from feedforward to feedback inhibition of hippocampal CA1 pyramidal cells. Eur J Neurosci 27:104-113. CrossRef Medline

Evstratova A, Chamberland S, Topolnik L (2011) Cell type-specific and activity-dependent dynamics of action potential-evoked Ca2 + signals in dendrites of hippocampal inhibitory interneurons. J Physiol 589:19571977. CrossRef Medline

Freund TF, Ylinen A, Miettinen R, Pitkänen A, Lahtinen H, Baimbridge KG, Riekkinen PJ (1992) Pattern of neuronal death in the rat hippocampus after status epilepticus: relationship to calcium binding protein content and ischemic vulnerability. Brain Res Bull 28:27-38. CrossRef Medline

Fuentealba P, Begum R, Capogna M, Jinno S, Márton LF, Csicsvari J, Thomson A, Somogyi P, Klausberger T (2008) Ivy cells: a population of nitric-oxide-producing, slow-spiking GABAergic neurons and their involvement in hippocampal network activity. Neuron 57:917-929. CrossRef Medline

Fuentealba P, Klausberger T, Karayannis T, Suen WY, Huck J, Tomioka R, Rockland K, Capogna M, Studer M, Morales M, Somogyi P (2010) Expression of COUP-TFII nuclear receptor in restricted GABAergic neuronal populations in the adult rat hippocampus. J Neurosci 30:1595-1609. CrossRef Medline

Garthwaite J (2008) Concepts of neural nitric oxide-mediated transmission. Eur J Neurosci 27:2783-2802. CrossRef Medline

Goldberg JH, Tamas G, Yuste R (2003) Ca2 + imaging of mouse neocortical interneurone dendrites: Ia-type $\mathrm{K}+$ channels control action potential backpropagation. J Physiol 551:49-65. CrossRef Medline

Gulyás AI, Megías M, Emri Z, Freund TF (1999) Total number and ratio of excitatory and inhibitory synapses converging onto single interneurons of different types in the CA1 area of the rat hippocampus. J Neurosci 19: 10082-10097. Medline

Hu H, Martina M, Jonas P (2010) Dendritic mechanisms underlying rapid synaptic activation of fast-spiking hippocampal interneurons. Science 327:52-58. CrossRef Medline

Jarsky T, Roxin A, Kath WL, Spruston N (2005) Conditional dendritic spike propagation following distal synaptic activation of hippocampal CA1 pyramidal neurons. Nat Neurosci 8:1667-1676. CrossRef Medline

Jensen K, Mody I (2001) L-type Ca2 + channel-mediated short-term plasticity of GABAergic synapses. Nat Neurosci 4:975-976. CrossRef Medline

Karagiannis A, Gallopin T, Dávid C, Battaglia D, Geoffroy H, Rossier J, Hillman EM, Staiger JF, Cauli B (2009) Classification of NPY-expressing neocortical interneurons. J Neurosci 29:3642-3659. CrossRef Medline

Karayannis T, Elfant D, Huerta-Ocampo I, Teki S, Scott RS, Rusakov DA, Jones MV, Capogna M (2010) Slow GABA transient and receptor desensitization shape synaptic responses evoked by hippocampal neurogliaform cells. J Neurosci 30:9898-9909. CrossRef Medline

Katona I, Rancz EA, Acsady L, Ledent C, Mackie K, Hajos N, Freund TF (2001) Distribution of CB1 cannabinoid receptors in the amygdala and their role in the control of GABAergic transmission. J Neurosci 21:95069518. Medline

Klausberger T (2009) GABAergic interneurons targeting dendrites of pyramidal cells in the CA1 area of the hippocampus. Eur J Neurosci 30:947957. CrossRef Medline

Klausberger T, Somogyi P (2008) Neuronal diversity and temporal dynamics: the unity of hippocampal circuit operations. Science 321:53-57. CrossRef Medline

Lenz RA, Wagner JJ, Alger BE (1998) N- and L-type calcium channel involvement in depolarization-induced suppression of inhibition in rat hippocampal CA1 cells. J Physiol 512:61-73. CrossRef Medline 
Llano I, Leresche N, Marty A (1991) Calcium entry increases the sensitivity of cerebellar Purkinje cells to applied GABA and decreases inhibitory synaptic currents. Neuron 6:565-574. CrossRef Medline

Maccaferri G, Lacaille JC (2003) Interneuron diversity series: hippocampal interneuron classifications-making things as simple as possible, not simpler. Trends Neurosci 26:564-571. CrossRef Medline

Makara JK, Katona I, Nyíri G, Németh B, Ledent C, Watanabe M, de Vente J, Freund TF, Hájos N (2007) Involvement of nitric oxide in depolarizationinduced suppression of inhibition in hippocampal pyramidal cells during activation of cholinergic receptors. J Neurosci 27:10211-10222. CrossRef Medline

Melzer S, Michael M, Caputi A, Eliava M, Fuchs EC, Whittington MA, Monyer H (2012) Long-range-projecting GABAergic neurons modulate inhibition in hippocampus and entorhinal cortex. Science 335:15061510. CrossRef Medline

Mizuseki K, Sirota A, Pastalkova E, Buzsáki G (2009) Theta oscillations provide temporal windows for local circuit computation in the entorhinalhippocampal loop. Neuron 64:267-280. CrossRef Medline

Nyíri G, Cserép C, Szabadits E, Mackie K, Freund TF (2005) CB1 cannabinoid receptors are enriched in the perisynaptic annulus and on preterminal segments of hippocampal GABAergic axons. Neuroscience 136:811-822. CrossRef Medline

Ohno-Shosaku T, Maejima T, Kano M (2001) Endogenous cannabinoids mediate retrograde signals from depolarized postsynaptic neurons to presynaptic terminals. Neuron 29:729-738. CrossRef Medline

Palmer RM, Ashton DS, Moncada S (1988) Vascular endothelial cells synthesize nitric oxide from L-arginine. Nature 333:664-666. CrossRef Medline

Pitler TA, Alger BE (1992) Postsynaptic spike firing reduces synaptic GABAA responses in hippocampal pyramidal cells. J Neurosci 12:41224132. Medline

Pouille F, Scanziani M (2001) Enforcement of temporal fidelity in pyramidal cells by somatic feed-forward inhibition. Science 293:1159-1163. CrossRef Medline

Price CJ, Cauli B, Kovacs ER, Kulik A, Lambolez B, Shigemoto R, Capogna M (2005) Neurogliaform neurons form a novel inhibitory network in the hippocampal CA1 area. J Neurosci 25:6775-6786. CrossRef Medline

Price CJ, Scott R, Rusakov DA, Capogna M (2008) GABA(B) receptor modulation of feedforward inhibition through hippocampal neurogliaform cells. J Neurosci 28:6974-6982. CrossRef Medline

Regehr WG, Carey MR, Best AR (2009) Activity-dependent regulation of synapses by retrograde messengers. Neuron 63:154-170. CrossRef Medline

Rozsa B, Zelles T, Vizi ES, Lendvai B (2004) Distance-dependent scaling of calcium transients evoked by backpropagating spikes and synaptic activity in dendrites of hippocampal interneurons. J Neurosci 24:661-670. CrossRef Medline

Soltesz I, Jones RS (1995) The direct perforant path input to CA1: excitatory or inhibitory? Hippocampus 5:101-103. CrossRef Medline

Szabadits E, Cserép C, Ludányi A, Katona I, Gracia-Llanes J, Freund TF, Nyíri G (2007) Hippocampal GABAergic synapses possess the molecular machinery for retrograde nitric oxide signaling. J Neurosci 27:8101-8111. CrossRef Medline

Tamás G, Lorincz A, Simon A, Szabadics J (2003) Identified sources and targets of slow inhibition in the neocortex. Science 299:1902-1905. CrossRef Medline

Taniguchi H, He M, Wu P, Kim S, Paik R, Sugino K, Kvitsiani D, Fu Y, Lu J, Lin Y, Miyoshi G, Shima Y, Fishell G, Nelson SB, Huang ZJ (2011) A resource of Cre driver lines for genetic targeting of GABAergic neurons in cerebral cortex. Neuron 71:995-1013. CrossRef Medline

Topolnik L, Chamberland S, Pelletier JG, Ran I, Lacaille JC (2009) Activitydependent compartmentalized regulation of dendritic $\mathrm{Ca} 2+$ signaling in hippocampal interneurons. J Neurosci 29:4658-4663. CrossRef Medline

Tricoire L, Vitalis T (2012) Neuronal nitric oxide synthase expressing neurons: a journey from birth to neuronal circuits. Front Neural Circuits 6:82. CrossRef Medline

Tricoire L, Pelkey KA, Daw MI, Sousa VH, Miyoshi G, Jeffries B, Cauli B, Fishell G, McBain CJ (2010) Common origins of hippocampal Ivy and nitric oxide synthase expressing neurogliaform cells. J Neurosci 30:21652176. CrossRef Medline

Vetter P, Roth A, Häusser M (2001) Propagation of action potentials in dendrites depends on dendritic morphology. J Neurophysiol 85:926-937. Medline

Vida I, Halasy K, Szinyei C, Somogyi P, Buhl EH (1998) Unitary IPSPs evoked by interneurons at the stratum radiatum-stratum lacunosummoleculare border in the CA1 area of the rat hippocampus in vitro. J Physiol 506:755-773. CrossRef Medline

Wilson RI, Nicoll RA (2001) Endogenous cannabinoids mediate retrograde signalling at hippocampal synapses. Nature 410:588-592. CrossRef Medline 